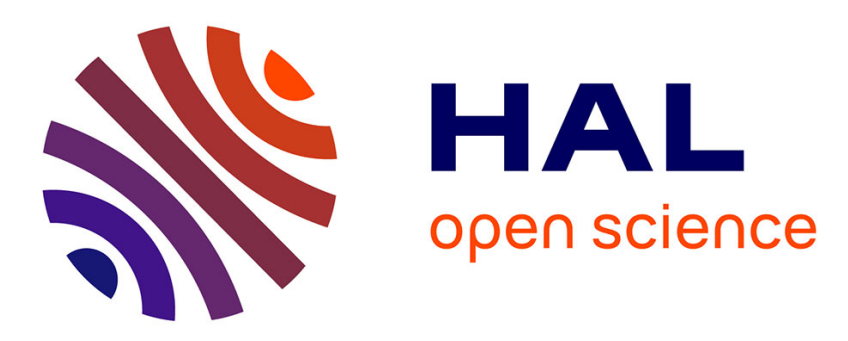

\title{
Illuminating of mild steel/HCI interface in the presence of 5-DAT inhibitor
}

\author{
G. Yerlikaya, A. Ahmad, M. Farsak, H. Akdas Kilig, G. Kardaş, S. Kaya
}

\section{To cite this version:}

G. Yerlikaya, A. Ahmad, M. Farsak, H. Akdas Kilig, G. Kardaş, et al.. Illuminating of mild steel/HCI interface in the presence of 5-DAT inhibitor. Journal of Molecular Liquids, 2021, 326, pp.115380. 10.1016/j.molliq.2021.115380 . hal-03130456

\section{HAL Id: hal-03130456 https://hal.science/hal-03130456}

Submitted on 19 Feb 2021

HAL is a multi-disciplinary open access archive for the deposit and dissemination of scientific research documents, whether they are published or not. The documents may come from teaching and research institutions in France or abroad, or from public or private research centers.
L'archive ouverte pluridisciplinaire HAL, est destinée au dépôt et à la diffusion de documents scientifiques de niveau recherche, publiés ou non, émanant des établissements d'enseignement et de recherche français ou étrangers, des laboratoires publics ou privés. 


\title{
Illuminating of Mild Steel/HCI Interface in The Presence of 5-DAT Inhibitor
}

Gurbet Yerlikaya ${ }^{\mathrm{a}, *}$, Abrar Ahmad $^{\mathrm{a}}$, Murat Farsak ${ }^{\mathrm{b}}$, Huriye Akdas Kilig ${ }^{\mathrm{c}, \mathrm{d}}$, Gülfeza Kardaş ${ }^{\mathrm{a}, *}$, Savaş Kaya ${ }^{\mathrm{e}}$

${ }^{a}$ Department of Chemistry, Faculty of Arts and Sciences, ÇukurovaUniversity, 01250, Adana, Turkey

${ }^{\mathrm{b}}$ Department of Food Technology, Applied Science School of Kadirli, Osmaniye Korkut Ata University, 80000, Osmaniye, Turkiye

${ }^{c}$ Department of Chemistry, Faculty of Arts and Sciences Y1ld1z Technical University, 34220 Esenler, Istanbul, Turkey

${ }^{\mathrm{d}}$ Chemical Sciences of Rennes, UMR 6226, CNRS-University of Rennes 1, Beaulieu Campus, 35042, Rennes cedex, France

${ }^{\mathrm{e}}$ Sivas Cumhuriyet University, Health Services Vocational School, Department of Pharmacy, 58140, Sivas, Turkey

\begin{abstract}
In this article, a novel and non-toxic Schiff base containing multi-heteroatom coded with the name 5-DAT (5-(4-(diethylamino)benzylidene)amino)-1,3,4-thiadiazole-2-thiol is designed as the corrosion inhibitor for mild steel (MS) in $1.0 \mathrm{M} \mathrm{HCl}$. The structure of Schiff base is illuminated by NMR, FT-IR, UV spectrophotometers and theoretical (Gaussian and Monte Carlo) calculations. Electrochemical techniques were utilized to determine the inhibition efficiency of synthesized Schiff base on mild steel corrosion. The surface of the MS was characterized by scanning electron microscopy. The inhibition talent of the 5-DAT was described by electrochemical impedance spectroscopy, lineer polarization resistance, and potentiodynamic polarization techniques. 5-DAT synthesized in this study showed high
\end{abstract}


efficiency with $98.9 \%$ inhibition efficiency since it contains high electron density heteroatoms such as nitrogen, sulfur and many multiple bonds, which are considered as more adsorption centers compared to the previous ones. While 5-DAT shows efficiency at $298 \mathrm{~K}$, according to EIS and LPR results, respectively, 98.41, 98.12; It was observed that the efficiency was not lost much with $93.87,92.86$ efficiencies at $328 \mathrm{~K}$. The presence of a 5-DAT film, which is homogeneously dispersed on the surface, protects the metal surface against corrosion.

Keywords: Mild steel; Schiff base; EIS; Polarization; Theoretical calculations. *Corresponding Author.

E-mail addresses: gurbet.yerlikaya@gmail.com, gulfeza@cu.edu.tr

\section{Introduction}

Corrosion problems in industries arise mainly due to cleaning mild steel surfaces, recalibrating and the use of hydrochloric acid $(\mathrm{HCl})$ in cleaning[1, 2]. Mild steel has a lot of usage areas such as industry and petroleum well. The cleaning of the mild steel is performed by acid. So, there is a corrosion risk in these areas. Therefore, the usage of organic inhibitors in acidic media is the most common of the various methods used to slow down and monitor acid corrosion[3, 4]. Organic compounds containing high-electron density heteroatoms, such as phosphorus, nitrogen, sulphur, oxygen, and multiple bonds considered as adsorption centers, have been shown to be effective as a corrosion inhibitor[5-8]. Besides, both nitrogen and sulfur-containing inhibitor molecules show better inhibition efficiency than those containing only $\mathrm{N}$ or $\mathrm{S}$ of these atoms[9-24]. The molecular structure of the compounds is of great importance in determining their inhibition performance in such studies. However, the protection mechanism of inhibitors in corrosion studies is not fully understood[25, 26]. Corrosion inhibition is generally considered to result from interactions between inhibitor molecules and the metal surface and a preventive surface film is formed[25]. Organic 
inhibitors reduce the corrosion rate by blocking active areas with 3 different methods. These methods include displacing water molecules, adsorbing them to the metal surface, and creating a compact barrier film on the metal surface[27-31]. Schiff bases can be applied for commercial purposes as they are cheap and non-toxicologically effective compounds that can be easily produced in large quantities by the process involving the binding of a carbonyl group and the enamine group in a suitable solvent[32].

It has been previously reported that various sulphur-containing Schiff bases that exhibit good corrosion inhibition in the acidic environment $[11,25,31]$. In this context, this study aims to design a novel, non-toxic Schiff base containing high electron density multi-heteroatom and many multiple bonds, which are considered as more adsorption centers to prevent mild steel corrosion. The inhibition efficiency of 5-DAT in $1.0 \mathrm{M} \mathrm{HCl}$ solution for mild steel is investigated via electrochemical impedance spectroscopy (EIS) and potentiodynamic polarization techniques. Also, theoretical calculations were carried out to define the adsorption mechanism of the inhibitor molecule to the metal surface. Theoretical calculations; while it successfully correlates chemical reactivity and selectivity with the molecular structure, it also enables the design of new inhibitor molecules for the corrosion prevention process. Based on this information, an idea is obtained about the mechanism of molecular level of the adsorption process.

\section{Experimental procedure}

\subsection{Preparation of working electrode}

The composition by weight of mild steel used for electrochemical measurements is C: $0.16 \%$, Si: 0.60, P: 0.04, Mn: 1.59, and Fe: 97.61. The working electrode was prepared to be $5 \mathrm{~cm}$ length from a cylindrical mild steel rod. The copper wire is tied to the top of the rod to ensure conductivity and is completely covered with polyester, except for the bottom surface of the 
rod with a surface area of $0.50 \mathrm{~cm}^{2}$. All analyses were performed from the open bottom surface. Before electrochemical measurements, the uncoated surface of mild steel was scraped and polished with 320, 600, and 1200 grid sandpaper, respectively. After polishing, the electrodes were cleaned by ethanol and distilled water to remove dirt and oil plates from the surface and quickly dipped in corrosion test solutions.

\subsection{Synthesis of 5-DAT}

5-amino-1,3,4-thiadiazole-2-thiol and 4-diethylaminobenzaldehyde were purchased from Sigma-Aldrich for 5-DAT synthesis and used as the initiator. Firstly, $6.06 \mathrm{mmol}$ of 4 diethylaminobenzaldehyde was added drop by drop to $4.56 \mathrm{mmol} 5$-amino-1,3,4-thiadiazole2-thiol under continuous stirring in $60 \mathrm{~mL}$ of ethanol and a few drops glacial acetic acid were added to the mixture to activate the aldehyde. It was then refluxed for 7 hours at $348 \mathrm{~K}$ and filtered. The orange solid product, reaction scheme is given in Fig. 1, was washed with distilled water and crystallized in ethanol to remove impurities. Then, the product was held on in a vacuum oven at $300 \mathrm{~K}$ for 4 days. Perkin-Elmer RX1-ATR model FT-IR spectroscopy device was used for the analysis of functional groups in the range of $4000-400 \mathrm{~cm}^{-1}$. The ${ }^{1} \mathrm{H}$ and ${ }^{13} \mathrm{C}$ NMR spectra were taken in $\left(\mathrm{CD}_{3}\right)_{2} \mathrm{SO}$ at $298 \mathrm{~K}$ by a Varian Mercury model $200 \mathrm{MHz}$ NMR spectrometer. UV-Vis spectra were taken with a Perkin-Elmer system.

\subsection{Electrochemical tests and characterization}

Electrochemical measurements have been completed by the Gamry interface 1000 potentiostat / galvanostat analyzer. Three electrode techniques were used for these measurements. The platinum, a total surface area of $2 \mathrm{~cm}^{2}$, was utilized as the counter electrode, while the $\mathrm{Ag} / \mathrm{AgCl}$ (3.0 M KCI) electrode was used as the reference electrode. The experiments were repeated three times to verify the reliability. The working electrode was immersed in the electrolyte for one hour to become a steady state of the electrode before experiments. The EIS measurements were performed at open circuit potential (OCP) by 
applying $10 \mathrm{mV}$ amplitude between $10^{5} \mathrm{~Hz}$ and $10^{-2} \mathrm{~Hz}$. Linear polarization resistance (LPR) measurements were realized with a scanning rate of $1.0 \mathrm{mV} \mathrm{s}^{-1}$ from $-10 \mathrm{mV}$ to $+10 \mathrm{mV}$ according to OCP. The slope of the LPR curves allows us to find the polarization resistance. The potentiodynamic polarization technique was performed with a scan rate of $1.0 \mathrm{mVs}^{-1}$ from OCP to $\pm 250 \mathrm{mV}$ to analyze corrosion parameters. An FEI Quanta 650 model field emission SEM was utilized to examine surface morphology.

\subsection{Theoretical evaluation of the structure of the molecule}

The theoretical calculation was carried out using the Gaussian 9.0[33]. Geometry optimizations of 5-DAT were made in the gas phase with Avogadro software[34]. The geometry of the compound was developed using the $3-21 \mathrm{G}$ basis set of Hartree Fock. The molecule was defined with the Gaussian 09W package in Gaussian view 5.0[35]. Electronic properties of the molecule were investigated with the lowest unoccupied molecular orbital $\left(\mathrm{E}_{\mathrm{LUMO}}\right)$, the energy of the highest occupied molecular orbital $\left(\mathrm{E}_{\mathrm{HOMO}}\right)$, and the energy gap $(\Delta \mathrm{E})$ between LUMO and HOMO, electronegativity $(\chi)$, global hardness $(\eta)$, dipole moment $(\mu)$.

The Monte Carlo simulation of studied inhibitor adsorption onto the Mild Steel surface[3]. In this work, we investigated the interaction with the Fe $\left(\begin{array}{lll}1 & 1 & 0\end{array}\right)$ surface and studied inhibitors using the adsorption locator module in the Materials Studio 2017 software[36-40]. All constituents of simulation systems were optimized by the Forcite module using COMPASS forcefield[41]. An Fe (110) crystal was built with a $30 \AA$ edge to achieve enough depth then enlarged to create a super cell $(12 \times 12)$. The optimized inhibitor molecule in the presence of 100 water molecules and $5 \mathrm{H}_{3} \mathrm{O}^{+}, 5 \mathrm{Cl}^{-}$ions, were made to adsorb onto the Fe (110) surface in order to find the most stable adsorbed configuration of studied molecule onto the surface of $\mathrm{Fe}$ (110) related to the higher negative adsorption energy values. 


\section{Results and discussions}

\subsection{Characterization of 5-DAT}

The structure of 5-DAT was defined by ${ }^{1} \mathrm{H}$ NMR, ${ }^{13} \mathrm{C}$ NMR and FT-IR. The FT-IR spectra of 5-DAT (Fig. 2) indicates band stretching around 3059, 2876, 1592, 1506, 1152 which corresponds to aromatic $\mathrm{C}-\mathrm{H}$ stretching, Aliphatic $\mathrm{C}-\mathrm{H}, \mathrm{C}=\mathrm{N}$ and $\mathrm{N}-\mathrm{H}$ stretching, respectively. Likewise, band stretching around 1042, 809, $699 \mathrm{~cm}^{-1}$ are related to monosubstituted aromatic C-H stretching [42]. According to the ${ }^{1} \mathrm{H}$ NMR spectrum of 5-DAT given in Fig. 3, at $\delta: 14.24$ ppm (s, H, C-SH ], 8.38 ppm [s, H, C-CH = N], 7.74 ppm [d, 2H, CH-CH-C, J = 8.8 Hz.], 6.77 ppm [d, 2H NC-CH, J = 9.2 Hz.], 3.45 ppm [q, 4H, $\mathrm{CH}_{3}-\mathrm{CH}_{2}-\mathrm{N}$, $\mathrm{J}=20.8 \mathrm{~Hz}.], 1.15 \mathrm{ppm}\left[\mathrm{t}, 6 \mathrm{H},-\mathrm{CH}_{3}, \mathrm{~J}=14 \mathrm{~Hz}\right.$.] indicates signals. According to the ${ }^{13} \mathrm{C} \mathrm{NMR}$ spectra of 5-DAT given in Fig.4 at $\delta: 185.52 \mathrm{ppm}[\mathrm{C}-\mathrm{SH}], 166.67 \mathrm{ppm}[\mathrm{SC}=\mathrm{N}], 165.95 \mathrm{ppm}$ $[\mathrm{CC}=\mathrm{N}], 151.80 \mathrm{ppm}[\mathrm{NC}-\mathrm{CH}], 132.68 \mathrm{ppm}[\mathrm{CH}-\mathrm{CC}=\mathrm{N}], 121.20 \mathrm{ppm}[-\mathrm{CH}-\mathrm{CC}=\mathrm{N}]$, $111.40 \mathrm{ppm}[\mathrm{C}-\mathrm{CH}-\mathrm{CH}] 44.41 \mathrm{ppm}\left[\mathrm{N}-\mathrm{CH}_{2} \mathrm{CH}_{3}\right], 12.66 \mathrm{ppm}\left[\mathrm{N}-\mathrm{CH}_{2} \mathrm{CH}_{3}\right]$ shows various signals.

\subsection{Electronic structure}

Absorption spectra of $3 \times 10^{-3} \mathrm{M}$ 5-DAT were obtained at room temperature in dichloromethane solution (Fig.5). In the electromagnetic spectrum, organic molecules usually give absorption peaks in the ultraviolet region $(200-350 \mathrm{~nm})$. However, in some case higher wavelength peaks can be obtained due to conjugation. Absorption spectra of the Schiff base showed an intense absorption band at $228-320 \mathrm{~nm}$ which is temporarily defined as the intraligand transition assigned to $\pi-\pi *$ transitions of benzene [43].

\subsection{Optical Band Gap}

The optical band gap was calculated by utilizing UV results and supplies insight into the use of the compound in the optical materials[44-46]. According to Fig.6, the optical bandgap is determined as $3.55 \mathrm{eV}$. This value indicates that the Schiff base is suitable for use in optical 
fields[44, 47]. According to the literature, it is ideal for the optical band to be in the range of 1.8-3.2 eV for use in optical fields[48, 49]. It has been observed that optical applications are not suitable when the optical band gap of the compound is greater than $4.0 \mathrm{eV}$. Studies have shown that when schiff bases are interacted with d10 metals such as $\mathrm{Cu}, \mathrm{Pt}, \mathrm{Ag}$ and doped with $\mathrm{TiO}_{2}$, the optical band gap falls from about $3.8 \mathrm{eV}$ to below $3.2 \mathrm{eV}[34,47]$. Optical band gap was calculated by the following Eq.:

$\alpha h v=\mathrm{B}\left(\mathrm{h} v-\mathrm{E}_{g}\right)^{n}$

In the above equation, $\alpha$ is absorption coefficient, $h v$ is energy of absorbed light, $E \mathrm{~g}$ and $B$ are optical band gap of material and a proportionality constant, respectively.

\subsection{Electrochemical tests}

The EIS technique is used to understand the corrosion process. The EIS results shed light on the resistive and capacitive behavior at the electrical double layer at the electrode/electrolyte interface can be effectively identified. Nyquist plot of mild steel without and with various concentrations $(0.5,1.0,2.0$, and $3.0 \mathrm{mM})$ of 5 -DAT in $1.0 \mathrm{M} \mathrm{HCl}$ are indicated in Fig.7. Increasing 5-DAT concentration in $1.0 \mathrm{M} \mathrm{HCl}$ solution has reasoned a change in Nyquist plots. The suppressed semicircular curve seeming in the Nyquist plots is concerned with charge transfer resistance, adsorption of 5-DAT molecules, and the entire cumulative species at the metal/solution interface[50,51]. According to the Nyquist plots, the difference between the lowest and the highest frequencies is called polarization resistance $(\mathrm{Rp})$, which is the sum of the charge transfer resistance, the diffusion resistance and the accumulation resistance. Fig.7 shows that $\mathrm{Rp}$ values increased with increasing 5-DAT concentration. Because a protective film has formed on the metal surface[52, 53]. This protective film provides a barrier to charge and mass transfer. An equivalent circuit diagram compatible with the results of MS electrodes in the presence of 5-DAT in 1.0 M HCI is shown in Fig. 8. The equivalent circuit diagram for mild steel in the absence of 5-DAT in 1.0 M HCI was not including the $\mathrm{CPE}_{\mathrm{f}}, \mathrm{n}_{\mathrm{f}}$ and $\mathrm{R}_{\mathrm{f}}$ in comparison with Fig.8. This diagram gives some parameters $\left(\mathrm{Rs}, \mathrm{R}_{\mathrm{P}}, \mathrm{CPE}\right.$, 
n) about the metal/solution interface[54-57]. Rs, $R_{c t}$ and $R_{f}$ are solution resistance, charge transfer resistance and film resistance respectively. $\mathrm{nf}$ is the inhomogeneity parameter of the film formed on the surface, while nct is the inhomogeneity of mild steel. In the equivalent circuit, the $\mathrm{C}$ was replaced with the $\mathrm{CPE}$ to create a matching junction representing the suppressed semicircles[58]. CPE is necessary for information on homogeneities such as porosity/surface roughness, diffusion or adsorption[59]. The impedance equation of CPE is given below:

$Z_{C P E}=\frac{1}{Y_{0}(J x W)^{n}}$

In the above equation can be described as $\mathrm{Y}_{0}$ is the magnitude of the $\mathrm{CPE}, \mathrm{j}$ is the imaginary unit $(\sqrt{ }(-1))$, w is the angular frequency, and $n$ is the phase shift expressing the degree of homogeneity of a surface[53, 60-62]. According to the LPR data and fitted EIS data, which are given in Table 1, it is seen that the $\mathrm{Rp}$ values increase with the increasing 5-DAT concentration, whereas the CPE values decrease.

The decrease in CPE may cause an increase in the thickness of the double layer and/or a decrease in the local dielectric constant due to the adsorption of the inhibitor at the metal / solution interface. The CPE is thought to symbolize a circuit parameter with restricting act as a resistor for $\mathrm{n}=0$, a capacitor for $\mathrm{n}=1$, and an inductor for $\mathrm{n}=-1$ [63]. However, $\mathrm{CPE}_{1}$ values decrease inversely with increasing concentration like $\mathrm{CPE}_{2}$. It shows that a more homogeneous surface occurred on the electrode with increasing concentration. It was observed that the inhibition efficiency $(\eta)$ values obtained from the LPR data were compatible and parallel with the EIS data. The inhibition efficiency calculated utilizing by equation (3);

$\eta \%=\left(\frac{R_{p}^{\prime}-R_{p}}{R_{P}^{\prime}}\right) \times 100$

In the equation, $\mathrm{R}_{\mathrm{p}}^{\prime}$ and $\mathrm{R}_{\mathrm{p}}$ refer to the polarization resistances of the mild steel in the inhibited and uninhibited medium, respectively. 


\subsection{Potentiodynamic Polarization}

The potentiodynamic polarization curves of the MS shown in Fig. 9 were obtained in the absence and presence of different concentrations $(0.5,1.0,2.0$, and $3.0 \mathrm{mM})$ of 5-DAT at 298 $\mathrm{K}$ in $1.0 \mathrm{M} \mathrm{HCl}$ solution.

The electrochemical parameters obtained from the Tafel region of cathodic polarization curves provide information about the kinetics of the metal dissolution process. The data in Table 2, which are corrosion potential $\left(\mathrm{E}_{\text {corr }}\right)$, inhibition efficiency $(\eta)$, corrosion current density $\left(\mathrm{i}_{\text {corr }}\right)$ and corrosion rate $(\mathrm{CR})$, are given information about the corrosion properties. . $i_{\text {corr }}$ values and corrosion rates are described as $\mu \mathrm{A} \mathrm{cm}^{-2}$ and $\mathrm{mm} \mathrm{year}^{-1}$, respectively as in the literature[64].

According to the potentiodynamic polarization curves of the cathodic and anodic branches, it was determined that the current densities decreased inversely with increasing 5-DAT concentrations. Positive shifts at corrosion potential were observed with increasing 5-DAT concentration. It is understood that 5-DAT is a anodic dominated mixed type inhibitor [65, 66].

It is claimed that in Fig.9, increasing current densities with polarization illustrated the activation controlled mechanism. And it was not affected by the presence of 5-DAT. However, it has seen that a linear Tafel curve has not observed in the anodic polarization curve. But current densities decreased with increasing 5-DAT concentrations. A number of calculated electrochemical parameters such as inhibition efficiency, $\mathrm{E}_{\mathrm{corr}}$ and $i_{\text {corr }}$, were shown in Table 2. The current densities decreased, while the inhibition efficiency increased with increasing inhibitor concentration. It is indicating that 5-DAT is adsorbed on the mild steel surface. Thus inhibition occurs[67, 68]. Percentage inhibition efficiency $(\eta \%)$ values for 5DAT were calculated using the equation below[69]. 
$\eta \%=\left(\frac{i_{\text {uninh }}-i_{\text {inh }}}{i_{\text {uninh }}}\right) \times 100$

In the above equation, $\eta$ is the inhibition efficiency, $i_{\text {inh }}$ and $i_{\text {uninh }}$ expressed the corrosion current densities in the presence and absence of 5-DAT, respectively.

The feasibility of 5-DAT inhibitor is highly dependent on the CR results and according to ASTM (G.102-89,1999) standards, the calculation of the corrosion rate can be calculated in a practical way by using the current density with the following equation[70].

$C_{R=} K_{1} \frac{i_{\text {corr }}}{\rho} E_{w}$

where, respectively, $K_{l}$ is conversion constant, $i_{c o r r}$ is corrosion current, $E_{W}$ is equivalent weight and $\rho$ is density of $\mathrm{Fe}\left(8.87 \mathrm{~g} \mathrm{~cm}^{-3}\right)$.

The inhibition efficiency results given in Table 2 show that the 5-DAT inhibitor forms a protective layer on the surface in an acidic environment, thus protecting the electrode surface to a great extent and reducing the rate of corrosion[71].

\subsection{Examining the relation with temperature}

EIS and LPR curves given in Fig.10 and Fig.11 were performed to examine the temperaturedependent inhibition efficiency of MS corrosion in the presence and absence of $3.0 \mathrm{mM} 5$ DAT inhibitor at given temperatures $(298,308,318$, and $328 \mathrm{~K})$. According to Table 3, it was seen that the inhibition efficiency of 5-DAT was inversely proportional to increasing temperature. This behavior can be expressed that the whole process including chemical reactions, electrochemical reactions, and transfer process of reactive sorts is gaining speed. Thereby, corrosion progresses fast on the steel surface with increasing temperature[72].

\subsection{Effect of time on inhibition effectiveness}

The toughness of 5-DAT was investigated in an experiment for 120 hours. And the obtained Rp values are shown in Fig.12. The obtained inhibition efficiencies from EIS data at the end of 1 hour $(98.0 \%)$ and 120 hours $(90.0 \%)$ showed that there was no major change at the 
electrode. Based on these data, it can be said that 5-DAT only forms a protective layer on the surface of the metal. The strong adsorption of the inhibitor causes to increase the corrosion resistance and durability of the electrode in an acidic environment.

\subsection{Potential of zero charge and mechanism of inhibition}

Generally, the corrosion prevention mechanism in an acidic environment is related to the adsorption of the inhibitor to the surface of the metal. The charge and nature of the metal, structure of the inhibitor, and the kind of the aggressive electrolyte are very effective in the adsorption process. The surface charge of the metal can be described using the equation(6) by the potential of zero charges (PZC);

$E_{r}=E_{o c p}-E_{q=0}=0$

In the above equation, $\mathrm{E}_{\mathrm{r}}$ is the rational corrosion potential of Antropov, $\mathrm{E}_{\mathrm{q}=0}$ is the PZC. By the position of corrosion potential $\left(\mathrm{E}_{\mathrm{ocp}}\right)$, the generated electric field at the metal/solution interface causes the surface charge of the metal. And it is determined by comparing the Eocp with the zero charge potential (EPZC). If $\mathrm{E}_{\mathrm{r}}$ is negative, the surface of the electrode is negatively charged and adsorption of cations is preferred. In contrast, if $E_{r}$ is positive, the adsorption of anions is preferred.

To specify the surface charge of the mild steel electrode, the $\mathrm{R}_{\mathrm{p}}$ values obtained by taking EIS measurements at varied potentials in the $1.0 \mathrm{M} \mathrm{HCl}$ solution containing $3.0 \mathrm{mM}$ 5-DAT were plotted against the potential. The maximum point obtained from the curve in Fig.13 shows $\mathrm{E}_{\mathrm{PZC}}[73-76]$. The OCP of the mild steel electrode is $-0.486 \mathrm{~V}$ and the zero-charge potential is $0.466 \mathrm{~V}$. OCP is more negative than zero charge potential. Accordingly, the 5-DAT molecules in the acidic environment are electrostatically directly attached to the metal surface $[2,65] . \mathrm{E}_{\mathrm{r}}$ $=-20 \mathrm{mV}$, it can be seen that electrode surface was loaded negatively. Therefore, the inhibitor molecule may be adsorbed to the metal surface through cations.

\subsection{Morphology of surface}


Changes on the surface of the MS electrode, which is kept for 24 hours in the presence and absence of inhibitor in 1.0 M HCl, are determined by SEM technique. And pictograms were given in Fig.14 (a) and (b), respectively. Due to the extreme dissolution of the surface of the electrode in a corrosive media, it is seen that a large number of pits are formed at different diameters and depths, and the surface is severely corroded. When the inhibitor is added to the medium, it is observed that the metal surface is preserved significantly. Both of the SEM pictograms were obtained under the same conditions (magnitude: 500x).

\subsection{EDX analysis}

EDX spectra were utilized to define which elements were present on the mild steel surface before and after exposure to the inhibitor solution. The results of EDX spectra are shown in Fig.15. The percentage atomic content of various elements of uninhibited and inhibited mild steel surface determined by EDX is shown in Table 4. The percentage atomic content of Fe for mild steel immersed in $1.0 \mathrm{M} \mathrm{HCl}$ without and with $3.0 \mathrm{M}$ of 5-DAT is $29.91 \%$ and $34,19 \%$, respectively. It is seen from Fig. 15 that the atomic Fe percentage of the inhibited sample is greater than that of the non-inhibited. The EDX spectra of inhibited mild steel include the peaks corresponding to all the elements present in the inhibitor molecules indicating the adsorption of inhibitory molecules on the mild steel surface.

\subsection{Theoretical calculations}

\subsubsection{Gaussian Calculation}

Calculated using Gaussian 09 program (Fig.16) -optimized structure, the lowest occupied $\left(\mathrm{E}_{\mathrm{LUMO}}\right)$ and highest unoccupied $\left(\mathrm{E}_{\mathrm{HOMO}}\right)$ molecular orbital energies for neutral and protonated 5-DAT molecule and mulliken atomic charges for neutral form are given in the

Fig.16. Some parameters such as electronegativity $(\chi)$, global softness $(S)$, global hardness $(\eta)$, the dipole moment $(\mu)$, the energy gap $(\Delta \mathrm{E}), \mathrm{E}_{\mathrm{HOMO}}, \mathrm{E}_{\mathrm{LUMO}}$, are calculated and given in Table 
5. Еномо generally provides information on the talent of inhibitor molecules to donate electrons to the unoccupied orbital of a metal[ 77,78$]$. Thus, the less negative values of $\mathrm{E}_{\mathrm{HOMO}}$ should increase the effectiveness of inhibition. Information on the reactivity, adsorption and electronic transitions between the HOMO and LUMO orbitals of a molecule can be obtained with the help of the $\Delta \mathrm{E}$ value[79, 80]. The inhibition activity of the protoned form is more than the neutral form. because low $\Delta \mathrm{E}$ facilitates adsorption and leads to an improvement in the reactivity of the molecule[80, 81]. HOMO and LUMO orbitals concentrated on the entire molecule, especially the rings. The polar-polar interaction between inhibitor/molecule is explained by the dipole moment. The dipole moment is demonstrating the polarity of polar covalent bonds. higher dipole moment values show the more efficient inhibitor interaction with the steel surface. 5-DAT molecule dipole moment is higher than the literature[72] and thus it is claimed that the more effective material for the corrosion inhibition. The softness and hardness value are related to the chemical reactivity and the ability to donate electrons, so these values give information about the corrosion prevention potential of the self-assembling molecule. Since molecules with large energy gaps are known to be hard [82, 83], it can be expressed that the neutral form is harder. Also, higher hardness in the molecule results in lower chemical reactivity and lower softness. The low hardness of the self-assembling molecule increases its corrosion prevention potential. Therefore, the softness of the protonated form is higher than the neutral form[84]. According to Epzc result, the inhibitor molecule may be adsorbed on the mild steel with cationic elements. When the Mulliken atomic charges were examined in Fig 16, it is seen that the $\mathrm{S}$ and $\mathrm{C}$ atoms have the highest positive charge $(0.490$ and 0.489). We combined the Epzc and gaussian results, the inhibitor adsorption on metal may occur between S-Fe and C-Fe atoms.

\subsubsection{Monte Carlo Simulation results}


In order to better understand the adsorption behavior of the examined inhibitor[85]. We have considered Monte Carlo simulations of the inhibitor molecule on Fe (110) surface in the presence of water molecules and $\mathrm{H}_{3} \mathrm{O}^{+}, \mathrm{Cl}^{-}$ions. The most stable low-energy adsorption of studied inhibitor ASAP on $\mathrm{Fe}(110) / 5 \mathrm{H}_{3} \mathrm{O}^{+}, 5 \mathrm{Cl}^{-}$ions $100 \mathrm{H}_{2} \mathrm{O}$ molecule system are shown in Fig. 17.

The corrosion inhibition action of 5-DAT on Mild Steel alloy in 1M HCl solution was studied theoretically using Monte Carlo simulation in order to confirm the result obtained experimentally. The higher adsorbed energy of 5-DAT inhibitor is a result of the strong interaction between $\mathrm{S}, \mathrm{N}$ atoms and $\pi$-electrons. These atoms, electron rich, can conjugate with iron atoms via unoccupied orbitals. Thus, the 5-DAT inhibitor occurs a barrier film on the Fe (110) surface[86]. Then, The 5-DAT adsorption energy is higher than $\mathrm{H}_{2} \mathrm{O}$ molecules (Table 6) and inhibitor molecules can substitute water molecules from the Fe (110) surface for that reason [87].

\section{Conclusion}

A new Schiff base called 5-DAT has been successfully synthesized. And spectroscopic methods, such as FT-IR and ${ }^{1} \mathrm{H}$ NMR and ${ }^{13} \mathrm{C}$ NMR have been used to elucidate the structure of the molecule. The inhibition behavior of 5-DAT on mild steel in the acidic environment was investigated using electrochemical measurements and SEM techniques. Theoretical calculations are given as complementary to the experimental results.

- It was observed that the inhibition efficiency of the 5-DAT molecule was directly proportional to increasing concentration and provided $98.9 \%$ protection with the $3 \mathrm{mM}$ inhibitor.

- According to the results obtained from EIS and LPR, the inhibition efficiency of 5DAT was inversely proportional to the temperature. 
- EIS measurements made over time showed that the inhibition efficiency decreased from $98.8 \%$ to $97.5 \%$ after 120 hours.

- Potentiodynamic polarization measurements appear to decrease CR from 17.58 to $0.297 \mathrm{~mm}$ year $^{-1}$ in the presence of 5-DAT. In addition, 5-DAT has been determined to act as a mixed type inhibitor.

- It was determined from the $\mathrm{E}_{\mathrm{PZC}}$ value that mild steel was negatively charged and the inhibitor approached the surface with a positive charge.

- SEM pictograms were taken at the end of the 24-hour dipping showed that mild steel was significantly corroded in the inhibitor-free solution and that the 5-DAT provided a well protection by forming a film on the surface.

- HOMO and LUMO nodes of 5-DAT molecules were delocalized on the rings.

- Epzc and theoretical calculations are compatible with each other and It is thought that the inhibitor molecule was bonded to the surface via $\mathrm{S}$ atom which has the highest positive value.

\section{Acknowledgement}

The author is very grateful for providing the opportunity to work in the Chemistry Department of Çukurova University and financial support to the Scientific Research Projects Unit of Çukurova University.

\section{References}

[1] S. Şafak, B. Duran, A. Yurt, G. Türkoğlu, Schiff bases as corrosion inhibitor for aluminium in $\mathrm{HCl}$ solution, Corrosion Science, 54 (2012) 251-259. 
[2] R. Yıldız, A. Döner, T. Doğan, İ. Dehri, Experimental studies of 2-pyridinecarbonitrile as corrosion inhibitor for mild steel in hydrochloric acid solution, Corrosion Science, 82 (2014) 125-132.

[3] I.B. Obot, N.O. Obi-Egbedi, Adsorption properties and inhibition of mild steel corrosion in sulphuric acid solution by ketoconazole: Experimental and theoretical investigation, Corrosion Science, 52 (2010) 198-204.

[4] D.Y. Gökmen Sigırcık, Tunc Tüken, Synthesis and inhibitory effect of N,N'-bis(1phenylethanol) ethylenediamine against steel corrosion in $\mathrm{HCl}$ Media, Corrosion Science, 120 (2017) 184-193.

[5] A. Dutta, S.K. Saha, P. Banerjee, A.K. Patra, D. Sukul, Evaluating corrosion inhibition property of some Schiff bases for mild steel in $1 \mathrm{M} \mathrm{HCl}$ : competitive effect of the heteroatom and stereochemical conformation of the molecule, RSC Advances, 6 (2016) 74833-74844.

[6] A. Singh, K.R. Ansari, M.A. Quraishi, S. Kaya, P. Banerjee, The effect of an Nheterocyclic compound on corrosion inhibition of J55 steel in sweet corrosive medium, New Journal of Chemistry, 43 (2019) 6303-6313.

[7] D.B. Tripathy, M. Murmu, P. Banerjee, M.A. Quraishi, Palmitic acid based environmentally benign corrosion inhibiting formulation useful during acid cleansing process in MSF desalination plants, Desalination, 472 (2019) 114128.

[8] C. Verma, J. Haque, M.A. Quraishi, E.E. Ebenso, Aqueous phase environmental friendly organic corrosion inhibitors derived from one step multicomponent reactions: A review, Journal of Molecular Liquids, 275 (2019) 18-40.

[9] M. Behpour, S.M. Ghoreishi, N. Soltani, M. Salavati-Niasari, The inhibitive effect of some bis-N,S-bidentate Schiff bases on corrosion behaviour of 304 stainless steel in hydrochloric acid solution, Corrosion Science, 51 (2009) 1073-1082. 
[10] H.H. Hassan, E. Abdelghani, M.A. Amin, Inhibition of mild steel corrosion in hydrochloric acid solution by triazole derivatives, Electrochimica Acta, 52 (2007) 6359-6366.

[11] S.M.A. Hosseini, A. Azimi, The inhibition of mild steel corrosion in acidic medium by 1-methyl-3-pyridin-2-yl-thiourea, Corrosion Science, 51 (2009) 728-732.

[12] A. Kosari, M.H. Moayed, A. Davoodi, R. Parvizi, M. Momeni, H. Eshghi, H. Moradi, Electrochemical and quantum chemical assessment of two organic compounds from pyridine derivatives as corrosion inhibitors for mild steel in $\mathrm{HCl}$ solution under stagnant condition and hydrodynamic flow, Corrosion Science, 78 (2014) 138-150.

[13] R. Solmaz, Investigation of corrosion inhibition mechanism and stability of Vitamin B1 on mild steel in 0.5M HCl solution, Corrosion Science, 81 (2014) 75-84.

[14] R. Yildiz, An electrochemical and theoretical evaluation of 4,6-diamino-2pyrimidinethiol as a corrosion inhibitor for mild steel in $\mathrm{HCl}$ solutions, Corrosion Science, 90 (2015) 544-553.

[15] A. Zarrouk, B. Hammouti, T. Lakhlifi, M. Traisnel, H. Vezin, F. Bentiss, New 1 H pyrrole-2,5-dione derivatives as efficient organic inhibitors of carbon steel corrosion in hydrochloric acid medium: Electrochemical, XPS and DFT studies, Corrosion Science, 90 (2015) 572-584.

[16] A. Zarrouk, H. Zarrok, Y. Ramli, M. Bouachrine, B. Hammouti, A. Sahibed-dine, F. Bentiss, Inhibitive properties, adsorption and theoretical study of 3,7-dimethyl-1-(prop-2-yn1-yl)quinoxalin-2(1H)-one as efficient corrosion inhibitor for carbon steel in hydrochloric acid solution, Journal of Molecular Liquids, 222 (2016) 239-252.

[17] L. Zhou, Y.-L. Lv, Y.-X. Hu, J.-H. Zhao, X. Xia, X. Li, Experimental and theoretical investigations of 1,3,5-tris(4-aminophenoxy)benzene as an effective corrosion inhibitor for mild steel in $1 \mathrm{M} \mathrm{HCl}$, Journal of Molecular Liquids, 249 (2018) 179-187. 
[18] C. Verma, E.E. Ebenso, Y. Vishal, M.A.Quraishi, Dendrimers: A new class of corrosion inhibitors for mild steel in $1 \mathrm{M} \mathrm{HCl}$ : Experimental and quantum chemical studies, Journal of Molecular Liquids, 224 (2016) 1282-1293.

[19] Z. Salarvand, M. Amirnasr, M. Talebian, K. Raeissi, S. Meghdadi, Enhanced corrosion resistance of mild steel in $1 \mathrm{M} \mathrm{HCl}$ solution by trace amount of 2-phenyl-benzothiazole derivatives: Experimental, quantum chemical calculations and molecular dynamics (MD) simulation studies, Corrosion Science, 114 (2017) 133-145.

[20] L.H. Madkour, S. Kaya, I.B. Obot, Computational, Monte Carlo simulation and experimental studies of some arylazotriazoles (AATR) and their copper complexes in corrosion inhibition process, Journal of Molecular Liquids, 260 (2018) 351-374.

[21] A. Mishra, C. Verma, H. Lgaz, V. Srivastava, M.A. Quraishi, E.E. Ebenso, Synthesis, characterization and corrosion inhibition studies of $\mathrm{N}$-phenyl-benzamides on the acidic corrosion of mild steel: Experimental and computational studies, Journal of Molecular Liquids, 251 (2018) 317-332.

[22] Z. Hu, Y. Meng, X. Ma, H. Zhu, J. Li, C. Li, D. Cao, Experimental and theoretical studies of benzothiazole derivatives as corrosion inhibitors for carbon steel in $1 \mathrm{M} \mathrm{HCl}$, Corrosion Science, 112 (2016) 563-575.

[23] H. Keleş, D.M. Emir, M. Keleş, A comparative study of the corrosion inhibition of low carbon steel in $\mathrm{HCl}$ solution by an imine compound and its cobalt complex, Corrosion Science, 101 (2015) 19-31.

[24] I. Ahamad, R. Prasad, M.A. Quraishi, Inhibition of mild steel corrosion in acid solution by Pheniramine drug: Experimental and theoretical study, Corrosion Science, 52 (2010) 30333041.

[25] M. Yadav, R.R. Sinha, S. Kumar, I. Bahadur, E.E. Ebenso, Synthesis and application of new acetohydrazide derivatives as a corrosion inhibition of mild steel in acidic medium: 
Insight from electrochemical and theoretical studies, Journal of Molecular Liquids, 208 (2015) 322-332.

[26] A. Kokalj, Is the analysis of molecular electronic structure of corrosion inhibitors sufficient to predict the trend of their inhibition performance, Electrochimica Acta, 56 (2010) 745-755.

[27] J. Aljourani, K. Raeissi, M.A. Golozar, Benzimidazole and its derivatives as corrosion inhibitors for mild steel in 1M HCl solution, Corrosion Science, 51 (2009) 1836-1843.

[28] F. Bentiss, M. Bouanis, B. Mernari, M. Traisnel, H. Vezin, M. Lagrenée, Understanding the adsorption of $4 \mathrm{H}-1,2,4$-triazole derivatives on mild steel surface in molar hydrochloric acid, Applied Surface Science, 253 (2007) 3696-3704.

[29] M. Lebrini, M. Lagrenée, H. Vezin, L. Gengembre, F. Bentiss, Electrochemical and quantum chemical studies of new thiadiazole derivatives adsorption on mild steel in normal hydrochloric acid medium, Corrosion Science, 47 (2005) 485-505.

[30] E.A. Noor, The inhibition of mild steel corrosion in phosphoric acid solutions by some N-heterocyclic compounds in the salt form, Corrosion Science, 47 (2005) 33-55.

[31] K. Stanly Jacob, G. Parameswaran, Corrosion inhibition of mild steel in hydrochloric acid solution by Schiff base furoin thiosemicarbazone, Corrosion Science, 52 (2010) 224-228.

[32] M. Behpour, S.M. Ghoreishi, N. Mohammadi, N. Soltani, M. Salavati-Niasari, Investigation of some Schiff base compounds containing disulfide bond as $\mathrm{HCl}$ corrosion inhibitors for mild steel, Corrosion Science, 52 (2010) 4046-4057.

[33] M. Frisch, G. Trucks, H. Schlegel, G. Scuseria, M. Robb, J. Cheeseman, G. Scalmani, V. Barone, B. Mennucci, G. Petersson, Gaussian 09 Revision D. 01, 2009, Gaussian Inc. Wallingford CT, DOI (2009). 
[34] G. Yerlikaya, E.B. Tapanyiğit, B. Güzel, O. Şahin, G. Kardaş, Synthesis of phosphinecontaining novel $\mathrm{Pd}(\mathrm{II})$ and $\mathrm{Ni}(\mathrm{II})$ complexes: Electrochemical, photophysical and quantum chemical studies, Journal of Molecular Structure, 1198 (2019) 126889.

[35] R. Dennington, T. Keith, J. Millam, GaussView, version 5, Semichem Inc.: Shawnee Mission, KS, DOI (2009).

[36] S. Kaya, L. Guo, C. Kaya, B. Tüzün, I.B. Obot, R. Touir, N. Islam, Quantum chemical and molecular dynamic simulation studies for the prediction of inhibition efficiencies of some piperidine derivatives on the corrosion of iron, Journal of the Taiwan Institute of Chemical Engineers, 65 (2016) 522-529.

[37] S.K. Saha, A. Dutta, P. Ghosh, D. Sukul, P. Banerjee, Adsorption and corrosion inhibition effect of Schiff base molecules on the mild steel surface in $1 \mathrm{M} \mathrm{HCl}$ medium: a combined experimental and theoretical approach, Phys Chem Chem Phys, 17 (2015) 56795690.

[38] A.K. Singh, S. Thakur, B. Pani, G. Singh, Green synthesis and corrosion inhibition study of 2-amino-N'-((thiophen-2-yl)methylene)benzohydrazide, New Journal of Chemistry, 42 (2018) 2113-2124.

[39] S.K. Saha, M. Murmu, N.C. Murmu, P. Banerjee, Evaluating electronic structure of quinazolinone and pyrimidinone molecules for its corrosion inhibition effectiveness on target specific mild steel in the acidic medium: A combined DFT and MD simulation study, Journal of Molecular Liquids, 224 (2016) 629-638.

[40] B. Xu, Y. Ji, X. Zhang, X. Jin, W. Yang, Y. Chen, Experimental and theoretical studies on the corrosion inhibition performance of 4-amino-N,N-di-(2-pyridylmethyl)-aniline on mild steel in hydrochloric acid, RSC Advances, 5 (2015) 56049-56059. 
[41] V. Srivastava, J. Haque, C. Verma, P. Singh, H. Lgaz, R. Salghi, M.A. Quraishi, Amino acid based imidazolium zwitterions as novel and green corrosion inhibitors for mild steel: Experimental, DFT and MD studies, Journal of Molecular Liquids, 244 (2017) 340-352.

[42] N.B. Colthup, Spectra-Structure Correlations in the Infra-Red Region, Journal Of The Optical Society Of America, 40 (1950) 397-401.

[43] Ş. Güveli, N. Özdemir, A. Koca, T. Bal-Demirci, B. Ülküseven, Spectroscopic, electrochemical and X-ray diffraction studies on nickel(II)-complexes of acetophenone thiosemicarbazones substituted six-carbon groups, Inorganica Chimica Acta, 443 (2016) 7-14. [44] J. Tauc, R. Grigorovici, A. Vancu, Optical properties and electronic structure of amorphous germanium, physica status solidi (b), 15 (1966) 627-637.

[45] J. Tauc, Optical properties and electronic structure of amorphous $\mathrm{Ge}$ and $\mathrm{Si}$, Materials Research Bulletin, 3 (1968) 37-46.

[46] M. Shkir, H. Abbas, Z.R. Khan, Effect of thickness on the structural, optical and electrical properties of thermally evaporated $\mathrm{PbI} 2$ thin films, Journal of Physics and Chemistry of Solids, 73 (2012) 1309-1313.

[47] M. Masjedi, N. Mir, E. Noori, T. Gholami, M. Salavati-Niasari, Effect of Schiff base ligand on the size and the optical properties of $\mathrm{TiO} 2$ nanoparticles, Superlattices and Microstructures, 62 (2013) 30-38.

[48] C.L. Linfoot, P. Richardson, T.E. Hewat, O. Moudam, M.M. Forde, A. Collins, F. White, N. Robertson, Substituted $[\mathrm{Cu}(\mathrm{I})(\mathrm{POP})($ bipyridyl)] and related complexes: synthesis, structure, properties and applications to dye-sensitised solar cells, Dalton Trans, 39 (2010) 8945-8956.

[49] T.S. Lobana, P. Kumari, R. Sharma, A. Castineiras, R.J. Butcher, T. Akitsu, Y. Aritake, Thiosemicarbazone derivatives of nickel and copper: the unprecedented coordination of furan 
ring in octahedral nickel(II) and of triphenylphosphine in three-coordinate copper(I) complexes, Dalton Trans, 40 (2011) 3219-3228.

[50] Q. Deng, N.-N. Ding, X.-L. Wei, L. Cai, X.-P. He, Y.-T. Long, G.-R. Chen, K. Chen, Identification of diverse 1,2,3-triazole-connected benzyl glycoside-serine/threonine conjugates as potent corrosion inhibitors for mild steel in HCl, Corrosion Science, 64 (2012) 64-73.

[51] H. Keleş, Electrochemical and thermodynamic studies to evaluate inhibition effect of 2[(4-phenoxy-phenylimino)methyl]-phenol in $1 \mathrm{M} \mathrm{HCl}$ on mild steel, Materials Chemistry and Physics, 130 (2011) 1317-1324.

[52] Y. Tang, X. Yang, W. Yang, R. Wan, Y. Chen, X. Yin, A preliminary investigation of corrosion inhibition of mild steel in $0.5 \mathrm{M} \mathrm{H} 2 \mathrm{SO} 4$ by 2-amino-5-(n-pyridyl)-1,3,4-thiadiazole: Polarization, EIS and molecular dynamics simulations, Corrosion Science, 52 (2010) 1801 1808.

[53] F. Bentiss, C. Jama, B. Mernari, H.E. Attari, L.E. Kadi, M. Lebrini, M. Traisnel, M. Lagrenée, Corrosion control of mild steel using 3,5-bis(4-methoxyphenyl)-4-amino-1,2,4triazole in normal hydrochloric acid medium, Corrosion Science, 51 (2009) 1628-1635.

[54] M. Murmu, S.K. Saha, N.C. Murmu, P. Banerjee, Effect of stereochemical conformation into the corrosion inhibitive behaviour of double azomethine based Schiff bases on mild steel surface in $1 \mathrm{~mol} \mathrm{~L}-1 \mathrm{HCl}$ medium: An experimental, density functional theory and molecular dynamics simulation study, Corrosion Science, 146 (2019) 134-151.

[55] M. Murmu, S.K. Saha, P. Bhaumick, N.C. Murmu, H. Hirani, P. Banerjee, Corrosion inhibition property of azomethine functionalized triazole derivatives in $1 \mathrm{~mol} \mathrm{~L}-1 \mathrm{HCl}$ medium for mild steel: Experimental and theoretical exploration, Journal of Molecular Liquids, 313 (2020) 113508. 
[56] J.A. Calderón, O.E. Barcia, O.R. Mattos, Reaction model for kinetic of cobalt dissolution in carbonate/bicarbonate media, Corrosion Science, 50 (2008) 2101-2109.

[57] S. Modiano, J.A. Carreño, C.S. Fugivara, A.V. Benedetti, O.R. Mattos, Effect of hydrogen charging on the stability of SAE 10B22 steel surface in alkaline solutions, Electrochimica Acta, 51 (2005) 641-648.

[58] B.V. Appa Rao, M.Y. Iqbal, B. Sreedhar, Electrochemical and surface analytical studies of the self-assembled monolayer of 5-methoxy-2-(octadecylthio)benzimidazole in corrosion protection of copper, Electrochimica Acta, 55 (2010) 620-631.

[59] W.J.L.F. Manseeld, Determination Of Corrosion Rates By Electrochemical Dc And Ac Methods, Corrosion Science, 21 (1981) 647-672.

[60] F. Bentiss, M. Lebrini, H. Vezin, F. Chai, M. Traisnel, M. Lagrené, Enhanced corrosion resistance of carbon steel in normal sulfuric acid medium by some macrocyclic polyether compounds containing a 1,3,4-thiadiazole moiety: AC impedance and computational studies, Corrosion Science, 51 (2009) 2165-2173.

[61] R. Solmaz, Investigation of the inhibition effect of 5-((E)-4-phenylbuta-1,3dienylideneamino)- 1,3,4-thiadiazole-2-thiol Schiff base on mild steel corrosion in hydrochloric acid, Corrosion Science, 52 (2010) 3321-3330.

[62] Y. Sürme, A.A. Gürten, E. Bayol, E. Ersoy, Systematic corrosion investigation of various $\mathrm{Cu}-\mathrm{Sn}$ alloys electrodeposited on mild steel in acidic solution: Dependence of alloy composition, Journal of Alloys and Compounds, 485 (2009) 98-103.

[63] J.-B. Jorcin, M.E. Orazem, N. Pébère, B. Tribollet, CPE analysis by local electrochemical impedance spectroscopy, Electrochimica Acta, 51 (2006) 1473-1479.

[64] H. Keleş, M. Keleş, Electrochemical investigation of a schiff base synthesized by cinnamaldehyde as corrosion inhibitor on mild steel in acidic medium, Research on Chemical Intermediates, 40 (2014) 193-209. 
[65] R. Solmaz, Investigation of adsorption and corrosion inhibition of mild steel in hydrochloric acid solution by 5-(4-Dimethylaminobenzylidene)rhodanine, Corrosion Science, 79 (2014) 169-176.

[66] E.A. Şahin, R. Solmaz, İ.H. Gecibesler, G. Kardaş, Adsorption ability, stability and corrosion inhibition mechanism of phoenix dactylifera extrat on mild steel, Materials Research Express, 7 (2020) 016585.

[67] G. Moretti, F. Guidi, F. Fabris, Corrosion inhibition of the mild steel in $0.5 \mathrm{M} \mathrm{HCl}$ by 2butyl-hexahydropyrrolo[1,2-b][1,2]oxazole, Corrosion Science, 76 (2013) 206-218.

[68] A.O. Yüce, E. Telli, B.D. Mert, G. Kardaş, B. Yazıcı, Experimental and quantum chemical studies on corrosion inhibition effect of 5,5 diphenyl 2-thiohydantoin on mild steel in $\mathrm{HCl}$ solution, Journal of Molecular Liquids, 218 (2016) 384-392.

[69] M.J. Bahrami, S.M.A. Hosseini, P. Pilvar, Experimental and theoretical investigation of organic compounds as inhibitors for mild steel corrosion in sulfuric acid medium, Corrosion Science, 52 (2010) 2793-2803.

[70] S.O.A. O. I. Sekunowo, G. I. Lawal, Potentiostatic-Polarisation-Responses-Of-MildSteel-In-Seawater-And-Acid-Environments.pdf, International Journal Of Scientific \& Technology Research 2(2013) 139-145.

[71] M. El Azzouzi, A. Aouniti, S. Tighadouin, H. Elmsellem, S. Radi, B. Hammouti, A. El Assyry, F. Bentiss, A. Zarrouk, Some hydrazine derivatives as corrosion inhibitors for mild steel in 1.0M HCl: Weight loss, electrochemichal, SEM and theoretical studies, Journal of Molecular Liquids, 221 (2016) 633-641.

[72] H.M. Abd El-Lateef, A.M. Abu-Dief, L.H. Abdel-Rahman, E.C. Sañudo, N. AliagaAlcalde, Electrochemical and theoretical quantum approaches on the inhibition of C1018 carbon steel corrosion in acidic medium containing chloride using some newly synthesized 
phenolic Schiff bases compounds, Journal of Electroanalytical Chemistry, 743 (2015) 120 133.

[73] M.A. Amin, S.S. Abd El-Rehim, E.E.F. El-Sherbini, R.S. Bayoumi, The inhibition of low carbon steel corrosion in hydrochloric acid solutions by succinic acid, Electrochimica Acta, 52 (2007) 3588-3600.

[74] A. Lukomska, J. Sobkowski, Potential of zero charge of monocrystalline copper electrodes in perchlorate solutions, Journal of Electroanalytical Chemistry, 567 (2004) 95102.

[75] M.M. Saleh, Inhibition of mild steel corrosion by hexadecylpyridinium bromide in $0.5 \mathrm{M}$ H2SO4, Materials Chemistry and Physics, 98 (2006) 83-89.

[76] L. Tang, X. Li, L. Li, G. Mu, G. Liu, The effect of 1-(2-pyridylazo)-2-naphthol on the corrosion of cold rolled steel in acid media, Materials Chemistry and Physics, 97 (2006) 301307.

[77] M. Finšgar, A. Lesar, A. Kokalj, I. Milošev, A comparative electrochemical and quantum chemical calculation study of BTAH and BTAOH as copper corrosion inhibitors in near neutral chloride solution, Electrochimica Acta, 53 (2008) 8287-8297.

[78] D. Daoud, T. Douadi, S. Issaadi, S. Chafaa, Adsorption and corrosion inhibition of new synthesized thiophene Schiff base on mild steel X52 in $\mathrm{HCl}$ and $\mathrm{H} 2 \mathrm{SO} 4$ solutions, Corrosion Science, 79 (2014) 50-58.

[79] R.G. Pearson, Recent Advances in the Concept of Hard and Soft Acids and Bases, Journal of Chemical Education, 64 (1987) 561-567.

[80] Z. Cao, Y. Tang, H. Cang, J. Xu, G. Lu, W. Jing, Novel benzimidazole derivatives as corrosion inhibitors of mild steel in the acidic media. Part II: Theoretical studies, Corrosion Science, 83 (2014) 292-298. 
[81] X. Li, X. Xie, S. Deng, G. Du, Two phenylpyrimidine derivatives as new corrosion inhibitors for cold rolled steel in hydrochloric acid solution, Corrosion Science, 87 (2014) 27 39.

[82] A. Dutta, S.K. Saha, P. Banerjee, D. Sukul, Correlating electronic structure with corrosion inhibition potentiality of some bis-benzimidazole derivatives for mild steel in hydrochloric acid: Combined experimental and theoretical studies, Corrosion Science, 98 (2015) 541-550.

[83] D. de la Fuente, I. Díaz, J. Simancas, B. Chico, M. Morcillo, Long-term atmospheric corrosion of mild steel, Corrosion Science, 53 (2011) 604-617.

[84] E. Arslan, A.A. Gürten, H.Z. Gök, M. Farsak, Electrochemical Study of Self-Assembled Aminothiol Substituted Phthalonitrile Layers for Corrosion Protection of Copper, ChemistrySelect, 2 (2017) 8256-8261.

[85] I.B. Obot, N.O. Obi-Egbedi, S.A. Umoren, The synergistic inhibitive effect and some quantum chemical parameters of 2,3-diaminonaphthalene and iodide ions on the hydrochloric acid corrosion of aluminium, Corrosion Science, 51 (2009) 276-282.

[86] L.C.M. M.M. Kabanda, M. Ozcan, F. Karadag, I. Dehri, I.B. Obot, E. E. Ebenso., Quantum Chemical Studies on the Corrosion Inhibition of Mild Steel by Some Triazoles and Benzimidazole Derivatives in Acidic Medium, Int. J. Electrochem. Sci., 7 (2012) 5035-5056.

[87] I.B. Obot, N.O. Obi-Egbedi, Anti-corrosive properties of xanthone on mild steel corrosion in sulphuric acid: Experimental and theoretical investigations, Current Applied Physics, 11 (2011) 382-392. 
Author statement

Gurbet YERLIKAYA :Synthesis, Methodology, Original draft preparation,

Conceptualization, Writing, Reviewing and Editing

Abrar AHMAD :Methodology and editing

Murat FARSAK :Original draft preparation, Investigation, editing

Huriye AKDAS KİLİG :Investigating

Gülfeza KARDAŞ :İnvestigating

Savaş Kaya :Monte Carlo Simulation 


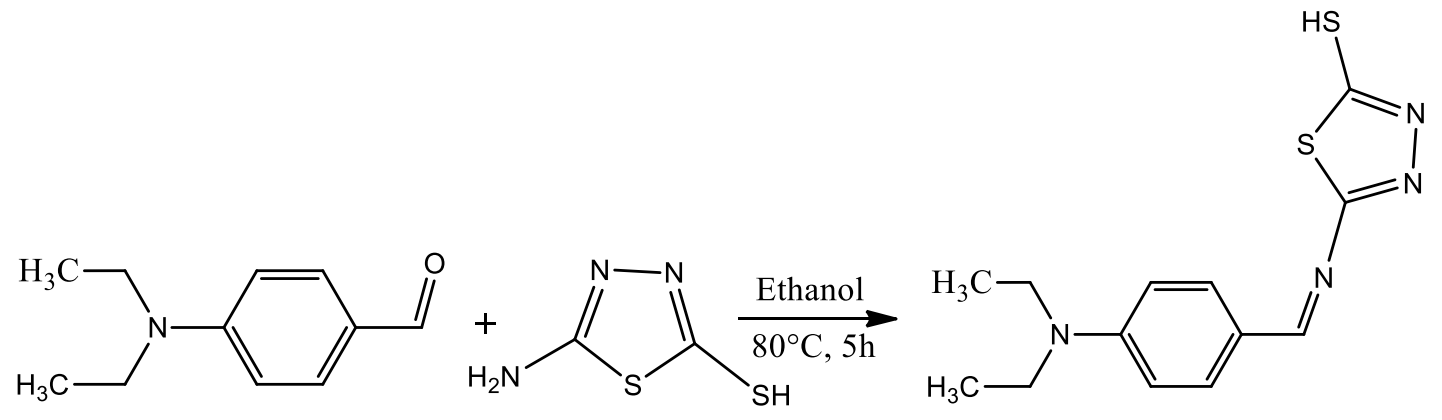

Fig. 1. Synthesis route of 5-DAT.

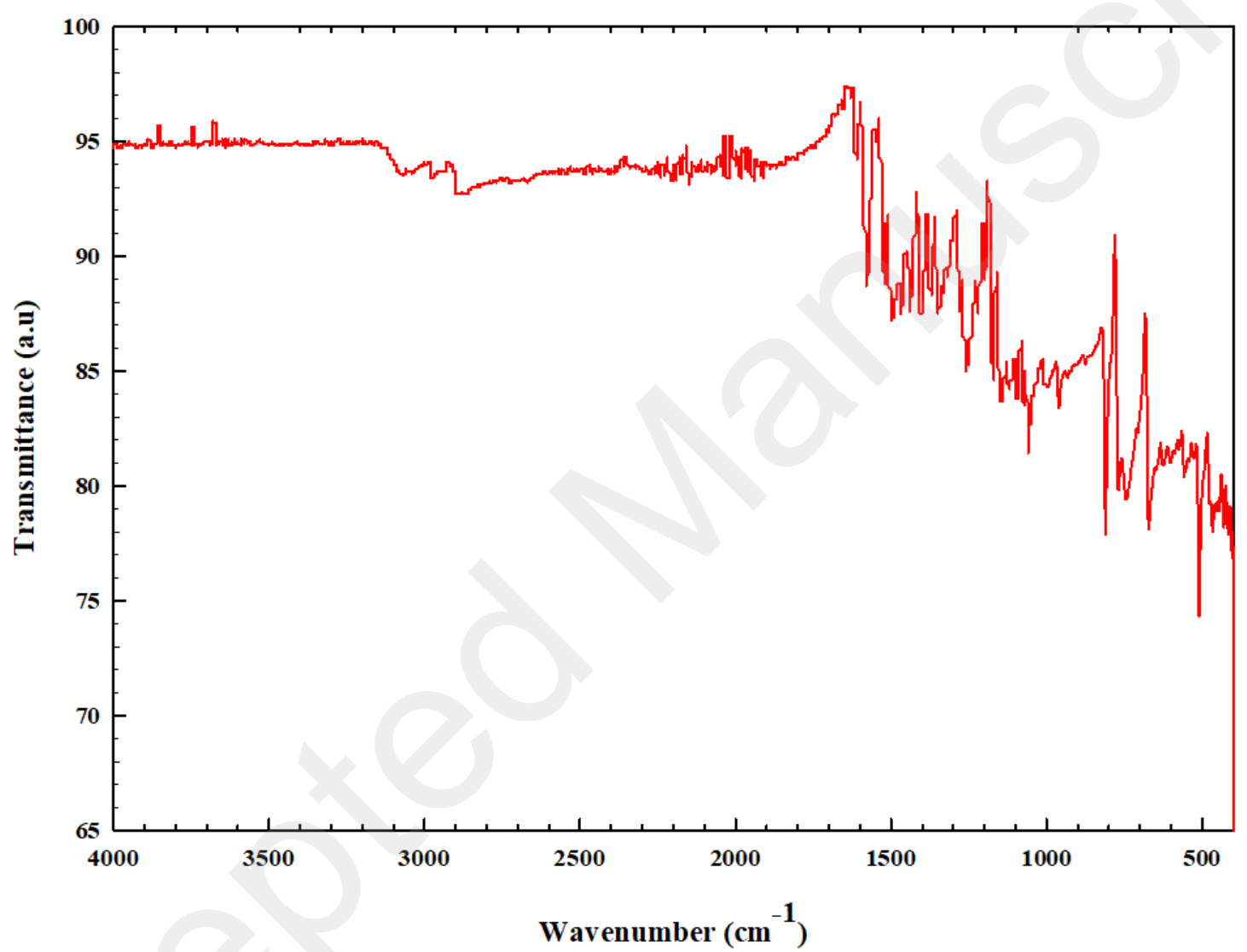

Fig. 2. FT-IR spectrum of synthesized 5-DAT. 

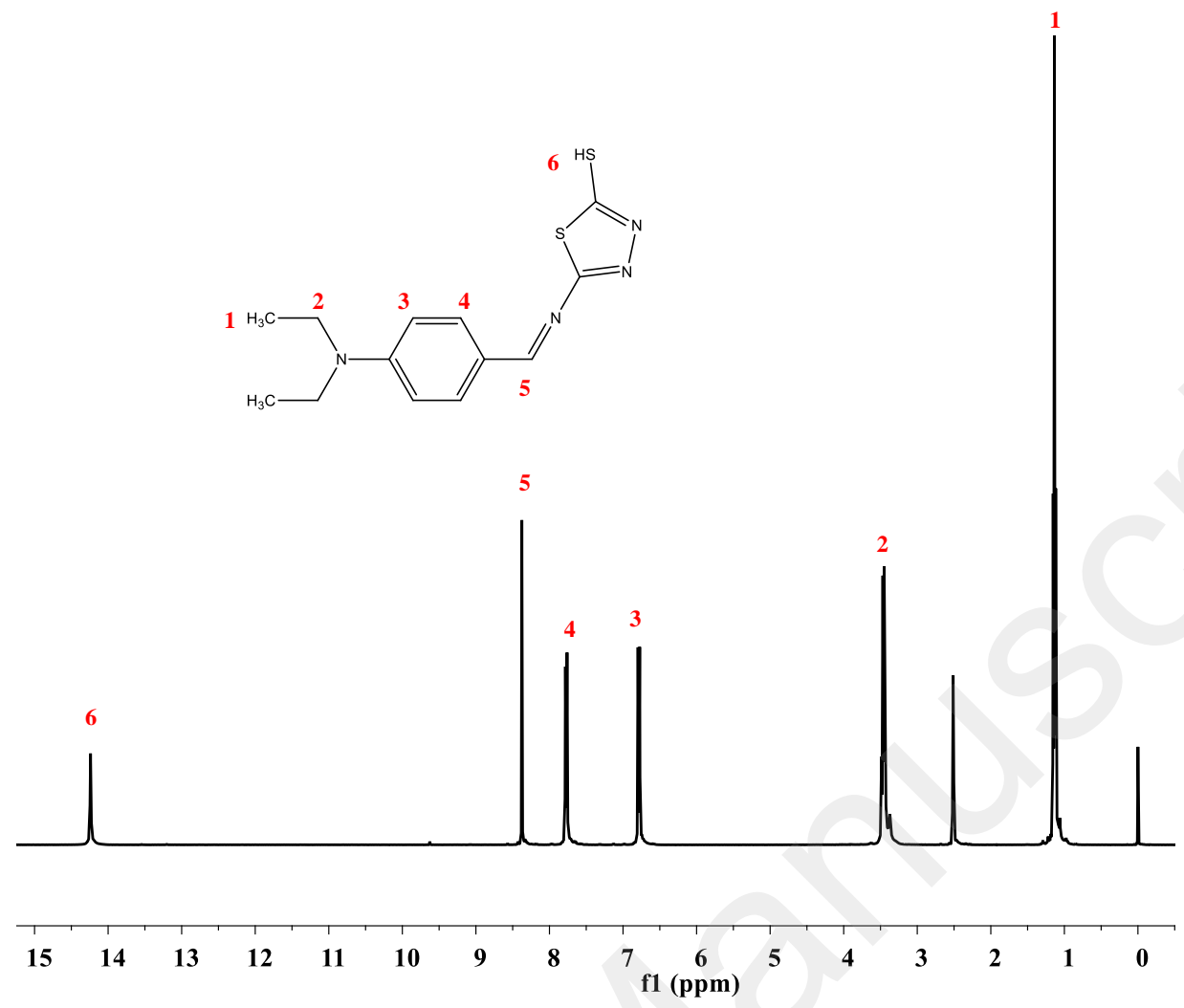

Fig. 3. ${ }^{1} \mathrm{H}$ NMR spectrum of synthesized 5-DAT.

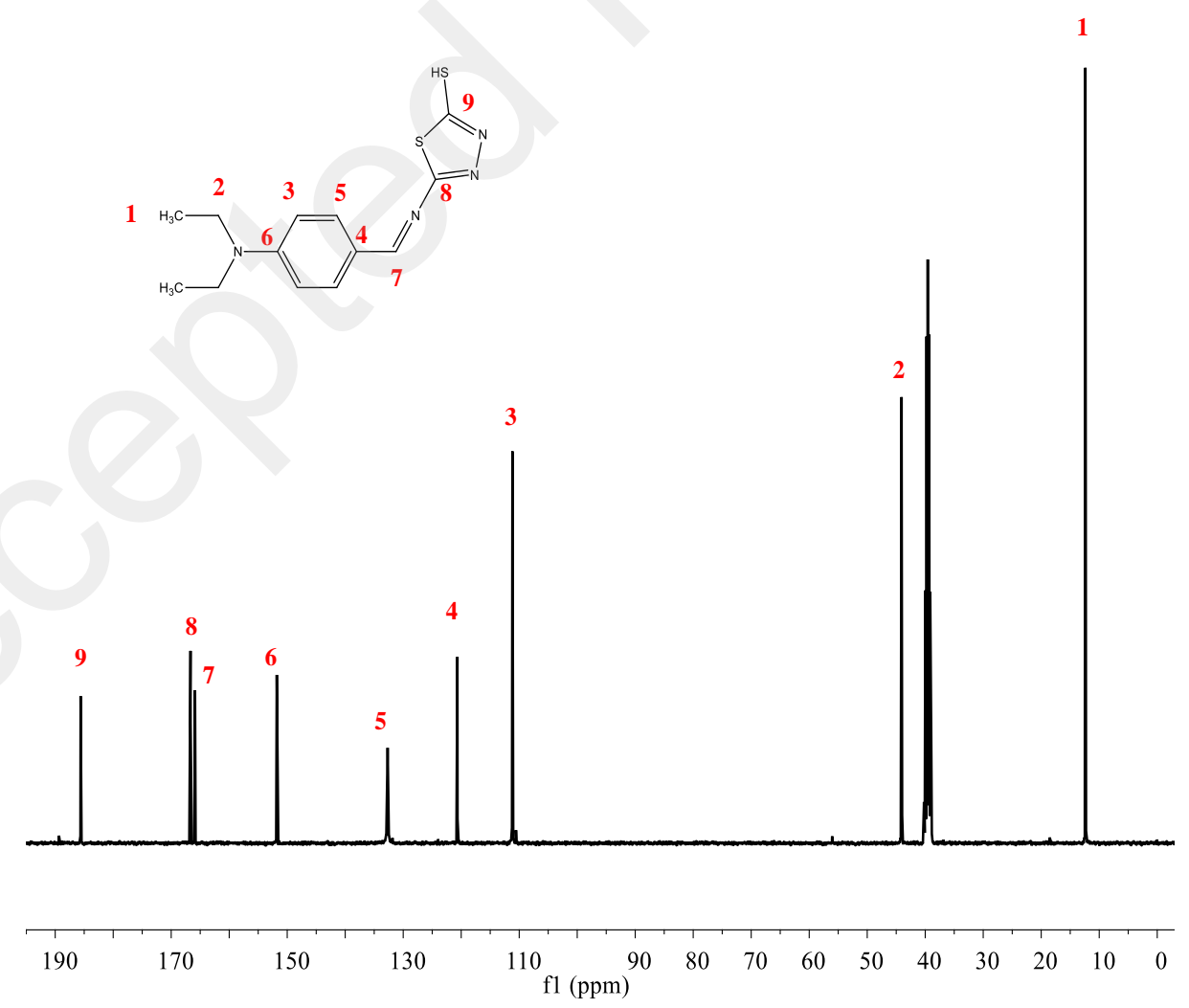

Fig.4. ${ }^{13} \mathrm{C}$ NMR spectrum of synthesized 5-DAT. 




Fig.5. UV- visible spectrum of 5-DAT

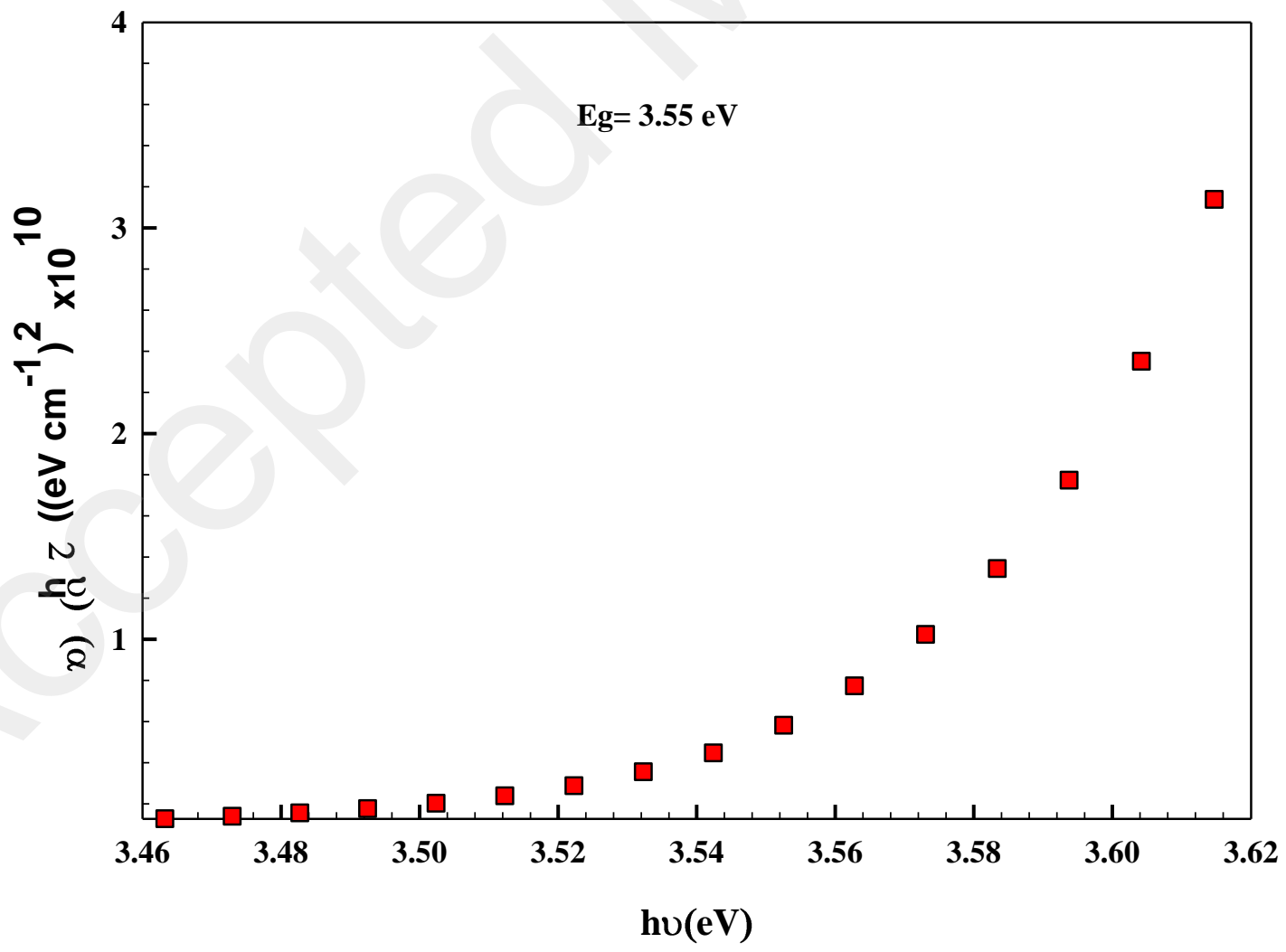

Fig.6. Optical band gap spectrum of 5-DAT 


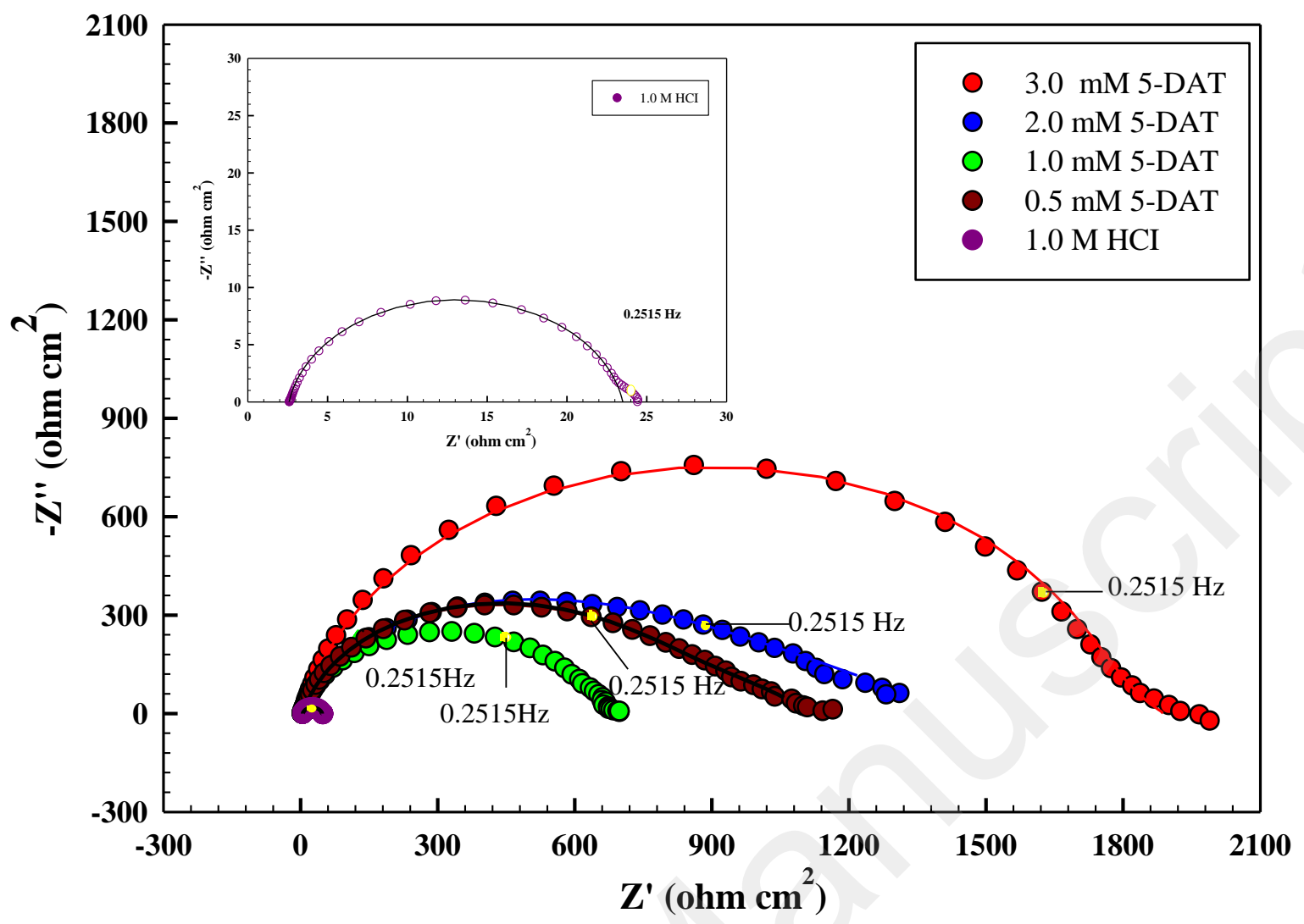

Fig.7. Nyquist plots of mild steel in the absence and presence of different concentrations of 5DAT in $1.0 \mathrm{M} \mathrm{HCl}$ solution at $298 \mathrm{~K}$.

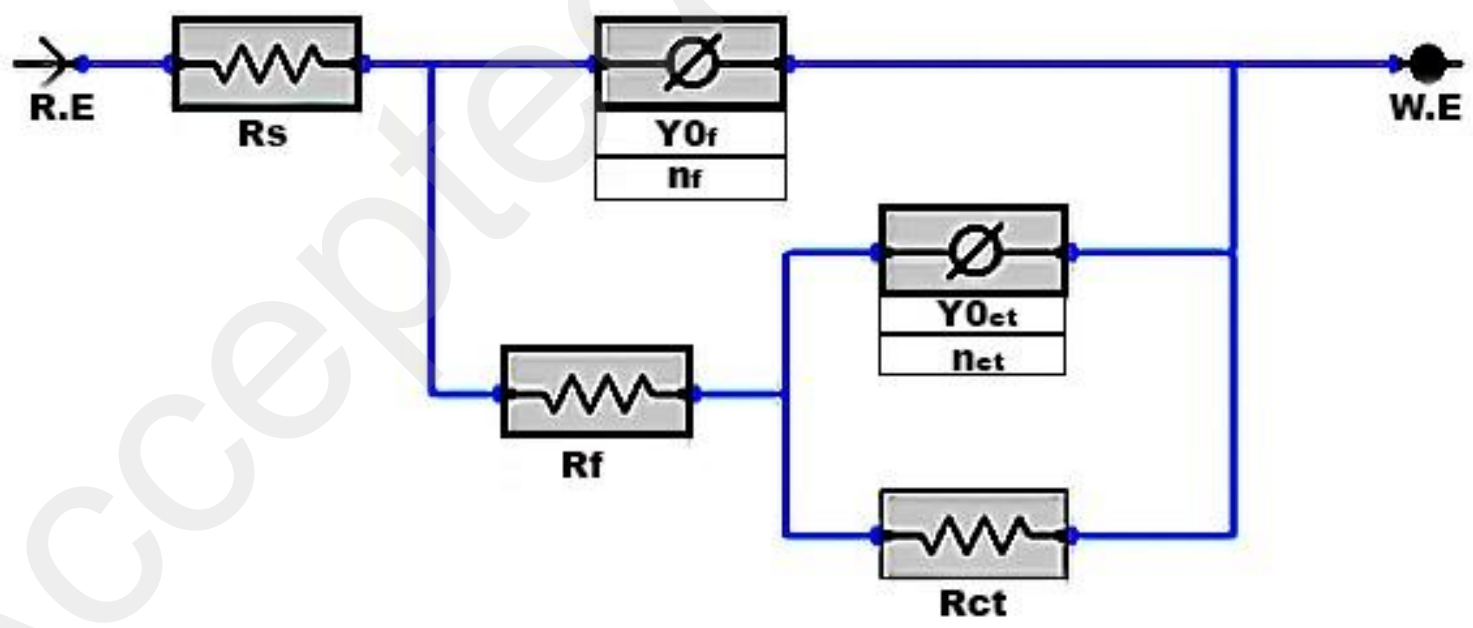

Fig 8. Electrical equivalent circuit model for 5-DAT in $1.0 \mathrm{M} \mathrm{HCl}$ at $298 \mathrm{~K}$. 




Fig. 9. Potentiodynamic polarization curves of mild steel in the absence and presence of different concentrations of 5-DAT in $1.0 \mathrm{M} \mathrm{HCl}$ solution at $298 \mathrm{~K}$. 

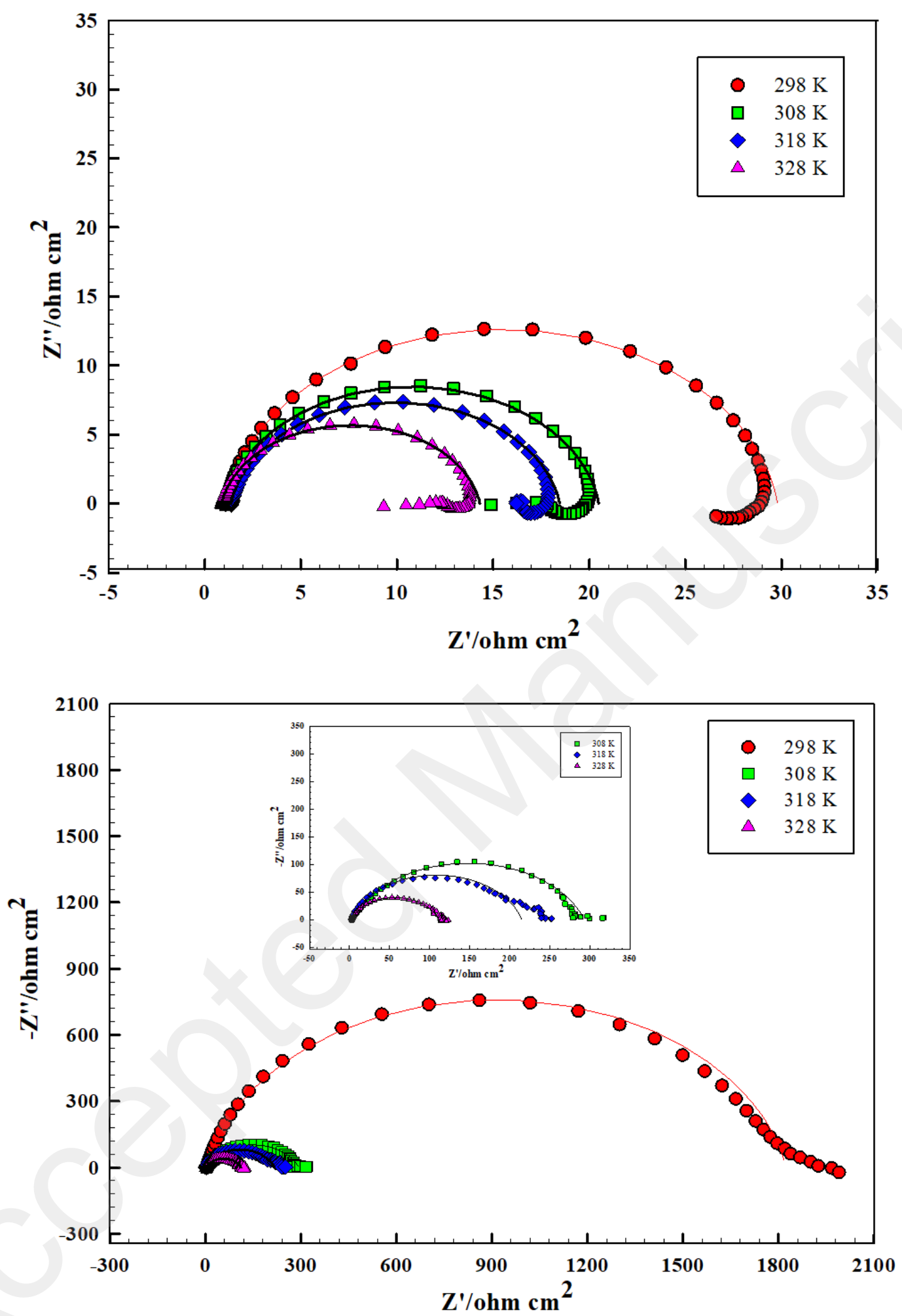

Fig.10. Nyquist plots of mild steel in the absence and presence of $3.0 \mathrm{mM}$ 5-DAT in 1.0 M $\mathrm{HCl}$ solution at different temperatures 

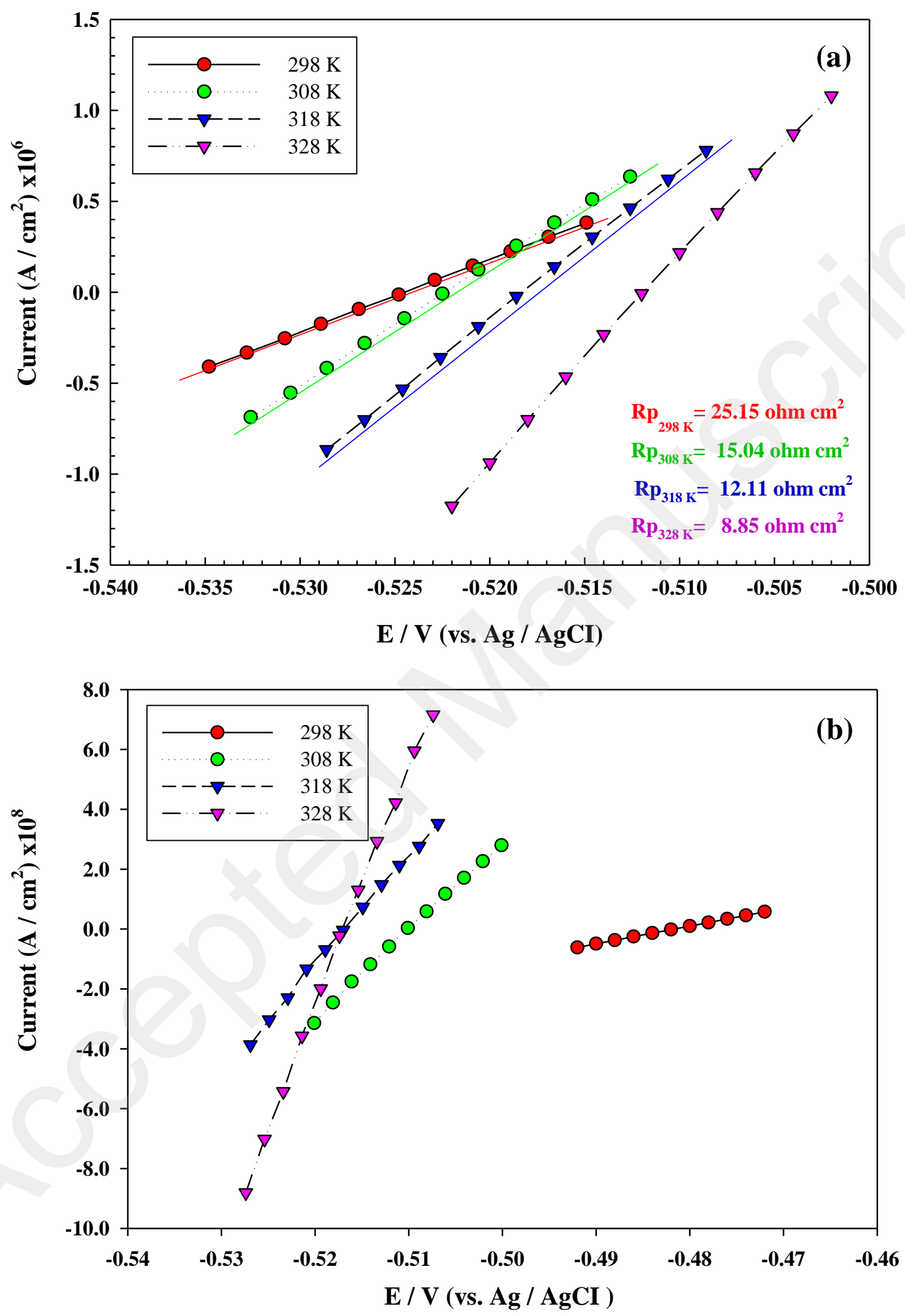

Fig.11. LPR plots of mild steel in the absence and presence of 3.0 mM 5-DAT in $1.0 \mathrm{M} \mathrm{HCl}$ solution at different temperatures 


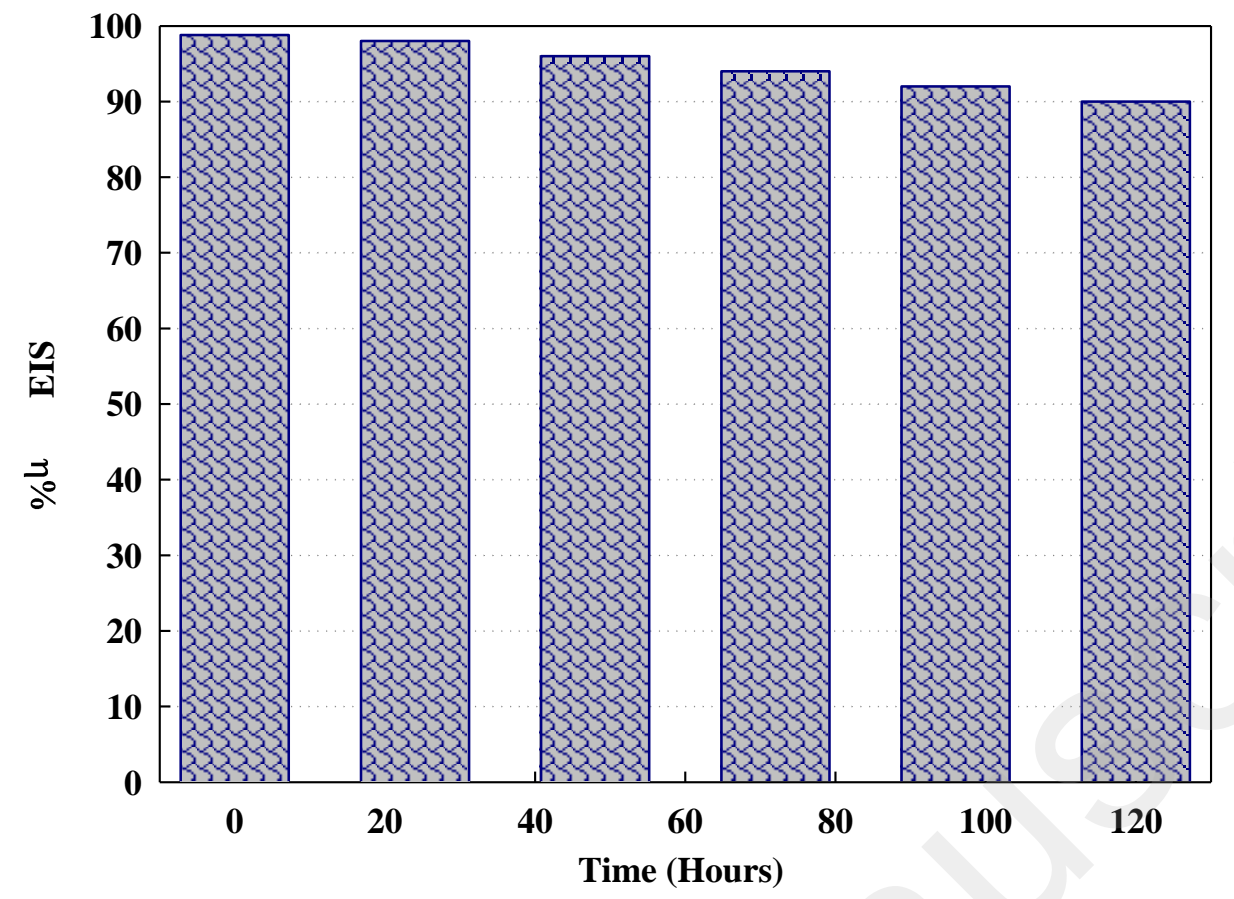

Fig. 12. Inhibition efficiency of mild steel in $1.0 \mathrm{M} \mathrm{HCI}$ solution containing $3.0 \mathrm{mM}$ of 5DAT at $298 \mathrm{~K}$

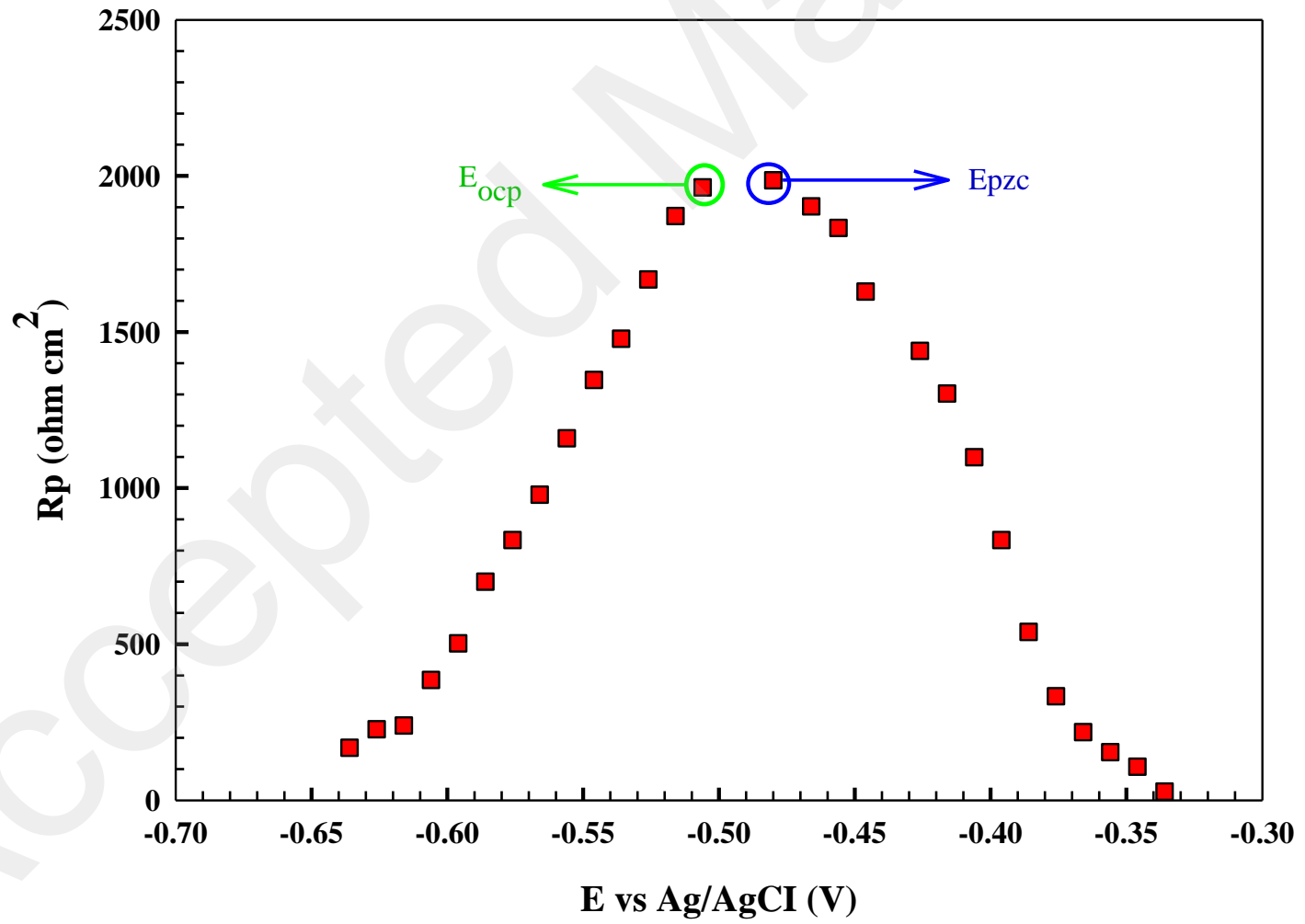

Fig. 13. Changing Rp values as a function of the applied potential in $1.0 \mathrm{M} \mathrm{HCl}$ with $3.0 \mathrm{mM}$ 5-DAT. 

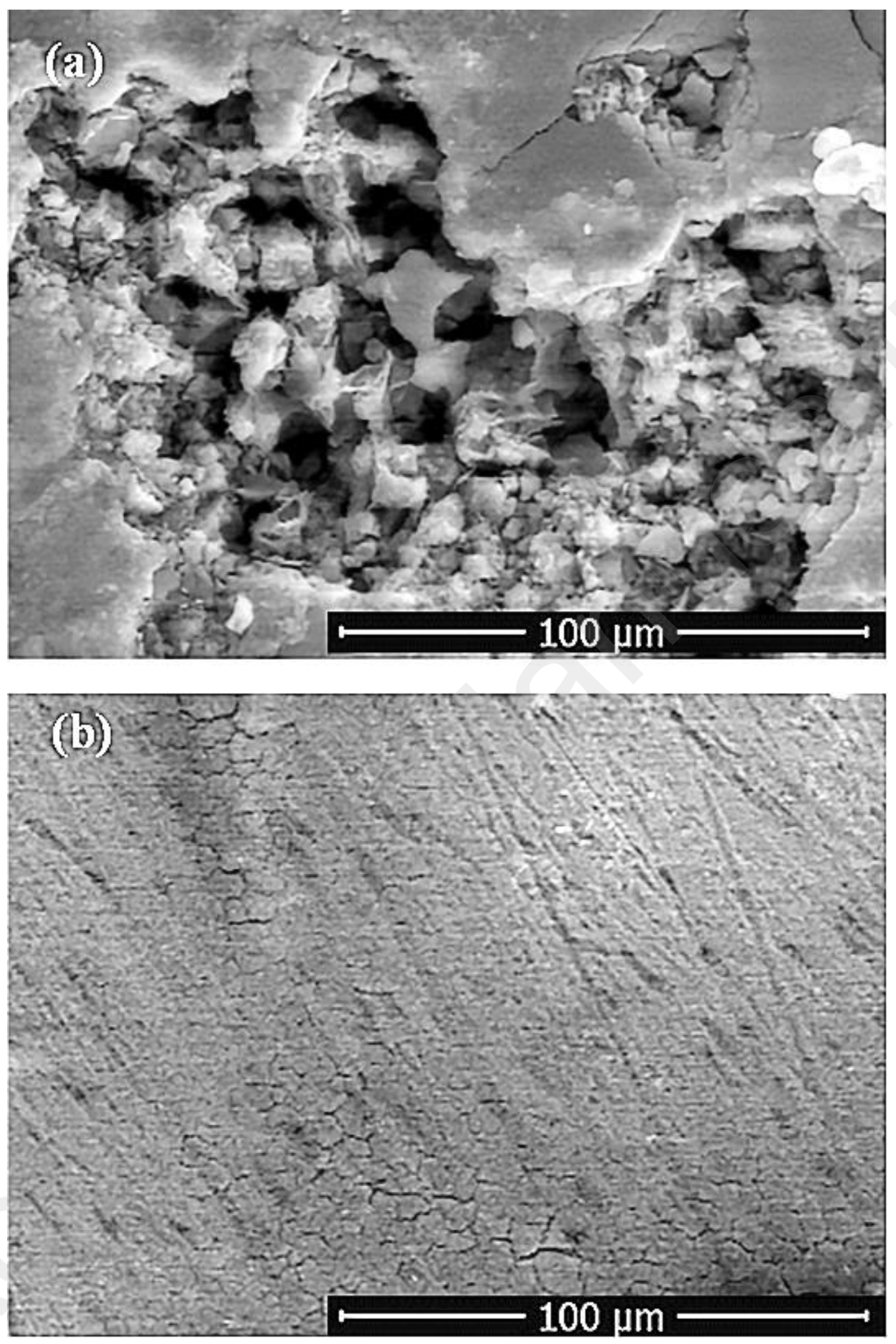

Fig. 14. SEM image of mild steel in $1.0 \mathrm{M} \mathrm{HCl}(\mathrm{a})$ and in the 3,0mM 5-DAT (b) at $298 \mathrm{~K}$ after immersion for 24 hours. 

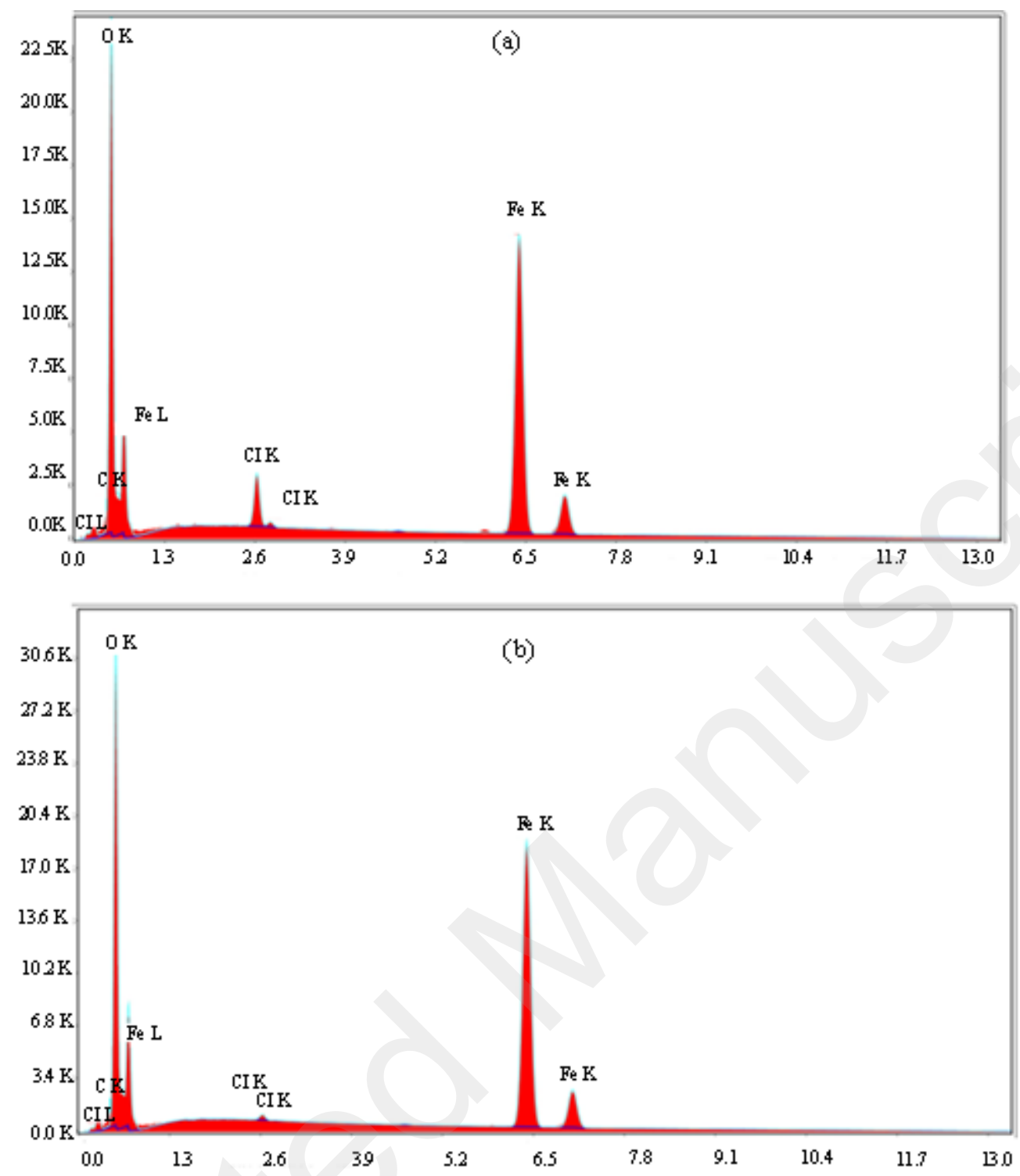

Fig.15. EDX result of mild steel in $1.0 \mathrm{M} \mathrm{HCl}(\mathrm{a})$ and in the 3.0mM 5-DAT (b) at $298 \mathrm{~K}$ after immersion for 24 hours. 

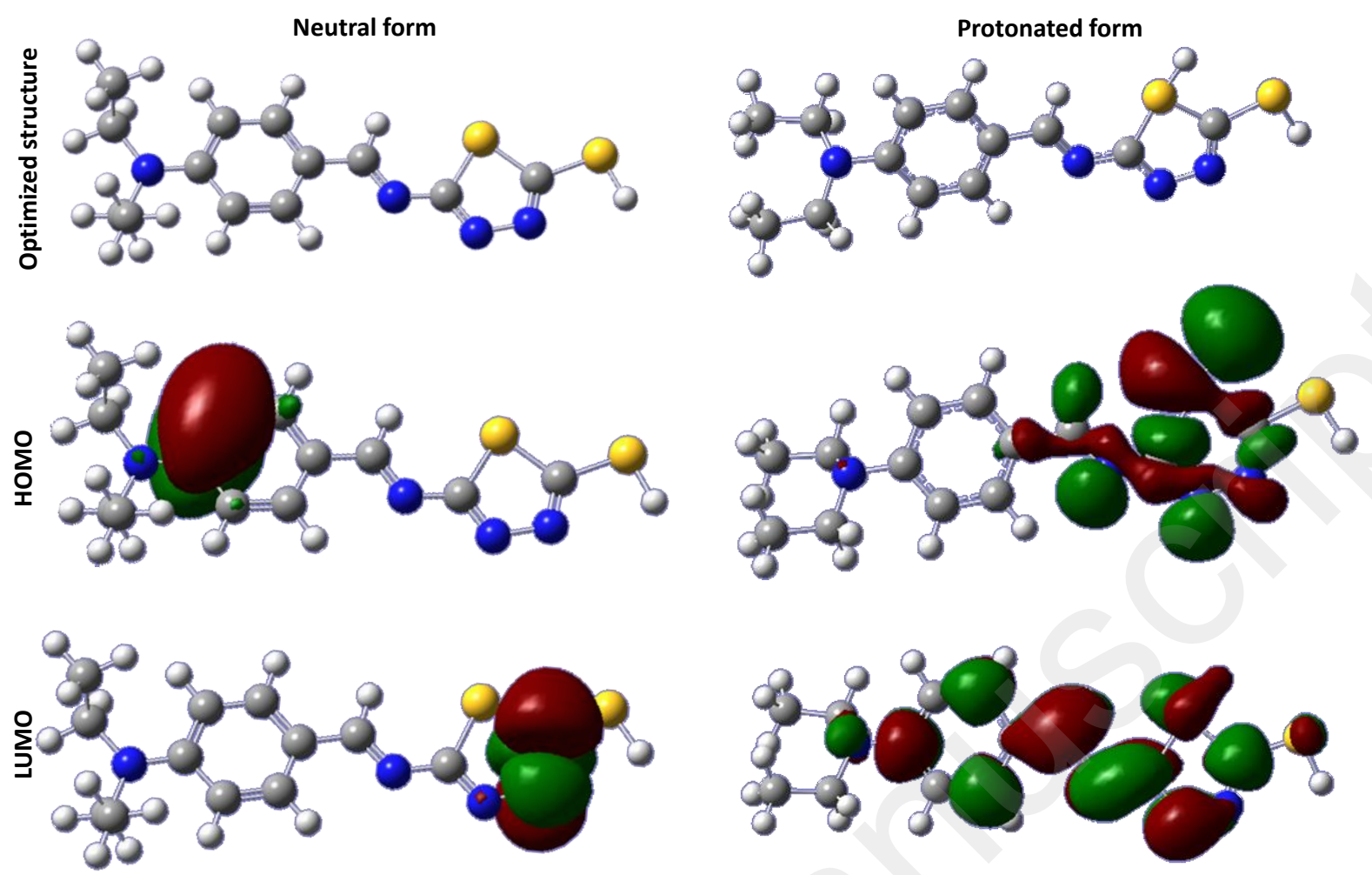

Mulliken atomic charges for neutral form



Fig.16. Optimized structure, HOMO and LUMO for neutral and protonated 5-DAT molecule and Mulliken atomic charges for neutral form 


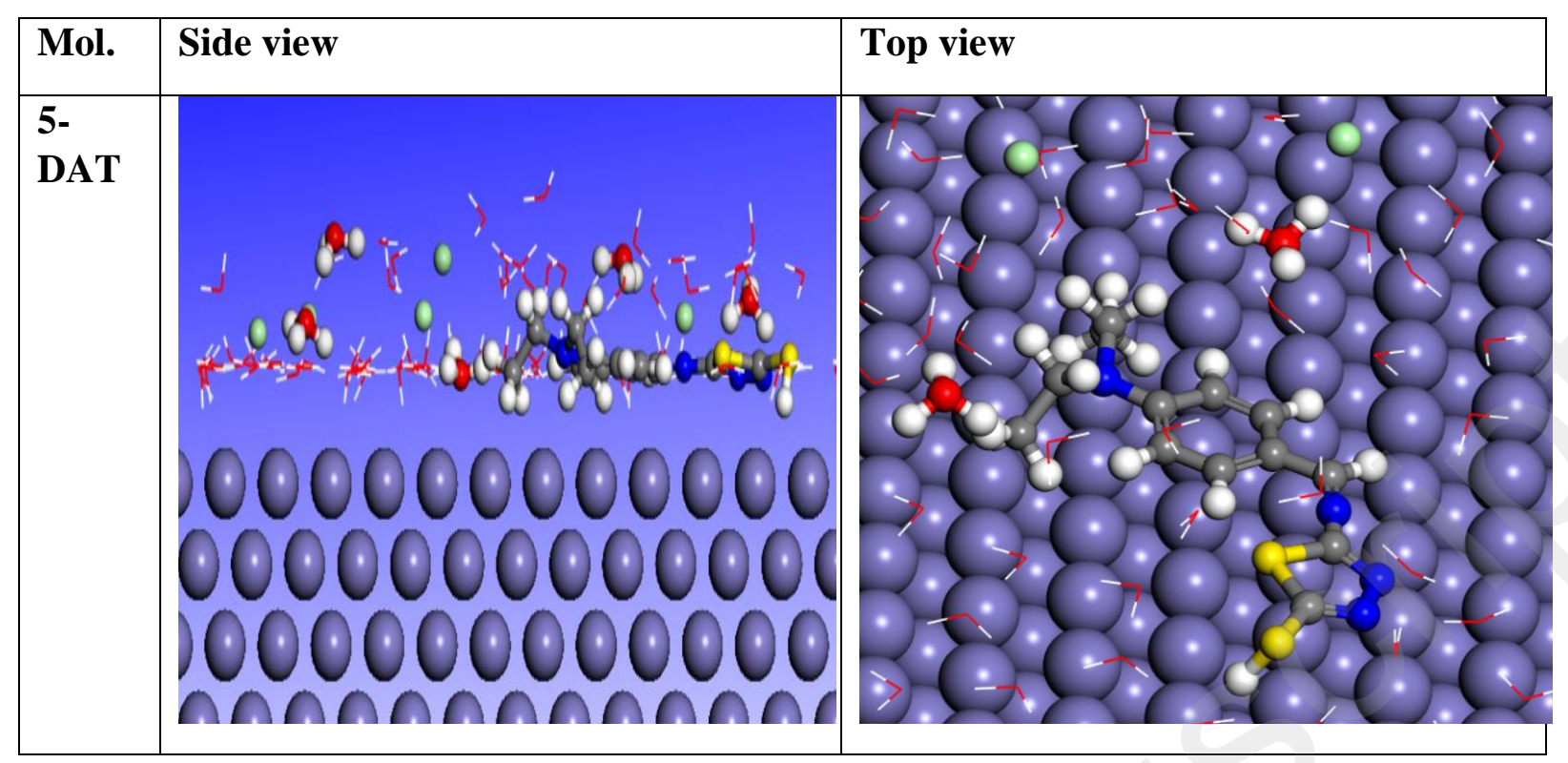

Fig.17. The most stable low energy configuration for the adsorption of studied molecule on $\mathrm{Fe}(110)$ surface obtained using the Monte Carlo simulation 
Table 1. The obtained EIS and LPR parameters

\begin{tabular}{|c|c|c|c|c|c|c|c|c|c|c|}
\hline \multirow{2}{*}{$\begin{array}{l}\text { Inhibitor } \\
\text { Concentra } \\
\text { tion } \\
\text { (mM) }\end{array}$} & \multirow[b]{2}{*}{ Rs } & \multicolumn{7}{|c|}{ EIS } & \multicolumn{2}{|c|}{ LPR } \\
\hline & & $\begin{array}{c}\mathrm{Rp} \\
\left(\Omega \mathrm{cm}^{2}\right. \\
)\end{array}$ & $\mathrm{n}_{\mathrm{ct}}$ & $n_{f}$ & $\begin{array}{c}\left(\mathrm{CPE}_{1}\right) \\
\mathrm{Y}^{\mathrm{o}}{ }_{\mathrm{ct}} \times 10^{5} \\
\Omega^{-1} \mathrm{~s}^{\mathrm{n}} \mathrm{cm}^{-2}\end{array}$ & $\begin{array}{c}\left(\mathrm{CPE}_{2}\right) \\
\mathrm{Y}_{\mathrm{f}}^{\circ} \times 10^{6} \Omega^{-1} \mathrm{~s}^{\mathrm{n}} \mathrm{c} \\
\mathrm{m}^{-2}\end{array}$ & $\begin{array}{c}\text { Chi- } \\
\text { Square } \\
\text { values }\end{array}$ & $\begin{array}{l}\eta_{\mathrm{EI}} \\
{ }_{s} \%\end{array}$ & $\begin{array}{c}\mathrm{Rp} \\
\left(\Omega \mathrm{cm}^{2}\right)\end{array}$ & $\begin{array}{c}\eta \\
\text { LPR } \\
\%\end{array}$ \\
\hline 0 & $\begin{array}{l}2 . \\
59\end{array}$ & 20.9 & $\begin{array}{l}0.8 \\
85\end{array}$ & --- & 262.7 & --- & $\begin{array}{c}309.6 \times 1 \\
0^{-6}\end{array}$ & - & 23.04 & \\
\hline 0.5 & $\begin{array}{l}2 . \\
83\end{array}$ & 553.6 & $\begin{array}{l}0.6 \\
42\end{array}$ & $\begin{array}{l}0.8 \\
82\end{array}$ & 2046 & 84.12 & $\begin{array}{l}115.6 \\
\times 10^{-6}\end{array}$ & $\begin{array}{c}96 \\
.2\end{array}$ & 479.8 & $\begin{array}{c}95 . \\
2\end{array}$ \\
\hline 1.0 & $\begin{array}{l}3 . \\
49\end{array}$ & 682.9 & $\begin{array}{l}0.6 \\
82\end{array}$ & $\begin{array}{l}0.8 \\
75\end{array}$ & 2678 & 53.01 & $\begin{array}{l}199.5 \\
\times 10^{-6}\end{array}$ & $\begin{array}{c}96 \\
.9\end{array}$ & 655.1 & $\begin{array}{c}96 . \\
5\end{array}$ \\
\hline 2.0 & $\begin{array}{l}5 . \\
58\end{array}$ & $\begin{array}{c}1416 . \\
6\end{array}$ & $\begin{array}{l}0.7 \\
29\end{array}$ & $\begin{array}{l}0.8 \\
56\end{array}$ & 1209 & 42.86 & $\begin{array}{l}154.9 \\
\times 10^{-6}\end{array}$ & $\begin{array}{l}98 \\
.5\end{array}$ & 1250.5 & $\begin{array}{c}98 . \\
2\end{array}$ \\
\hline 3.0 & $\begin{array}{l}3 . \\
96\end{array}$ & $\begin{array}{c}1867 . \\
3\end{array}$ & $\begin{array}{l}0.8 \\
83\end{array}$ & $\begin{array}{l}0.8 \\
96\end{array}$ & 26.8 & 31.93 & $\begin{array}{l}792.1 \\
\times 10^{-6}\end{array}$ & $\begin{array}{l}98 \\
.9\end{array}$ & 1684.6 & $\begin{array}{c}98 . \\
6\end{array}$ \\
\hline
\end{tabular}

Table 2. Calculated data from the potentiodynamic polarization curves

\begin{tabular}{|c|c|c|c|c|c|}
\hline $\begin{array}{c}\text { Inhibitor } \\
\text { Concentration } \\
\text { (mM) }\end{array}$ & $\begin{array}{c}\text { Ecorr } \\
(\mathrm{V}, \mathrm{Ag} / \mathrm{AgCl})\end{array}$ & $\begin{array}{c}i_{\text {corr }} \\
\left(\mu \mathrm{Am}^{-2}\right)\end{array}$ & $\begin{array}{l}\text { Corrosion rate } \\
\left(\mathrm{mm} \text { year }{ }^{-1)}\right.\end{array}$ & $\begin{array}{c}\text { Bc } \\
(\mathrm{mV})\end{array}$ & $\begin{array}{c}n \\
(\%)\end{array}$ \\
\hline 0 & -0.505 & 1670 & 17.58 & 170.2 & \\
\hline 0.5 & -0.507 & 92.2 & 0.952 & 101.9 & 94.5 \\
\hline 1.0 & -0.512 & 68.1 & 0.717 & 102.7 & 95.9 \\
\hline 2.0 & -0.508 & 37.5 & 0.395 & 108.0 & 97.8 \\
\hline 3.0 & -0.490 & 28.2 & 0.297 & 109.5 & 98.1 \\
\hline
\end{tabular}

Table 3. Obtained EIS and LPR results at different temperatures

\begin{tabular}{cccccc}
\hline & & \multicolumn{2}{c}{ EIS } & \multicolumn{2}{c}{ LPR } \\
\cline { 3 - 6 } Inhibitor & Temprature (K) & Rp & $\eta_{\text {EIS } \%}$ & Rp & $\eta_{\text {LPR }}$ \\
\hline Blank & 298 & 29.79 & & 25.15 &
\end{tabular}




\begin{tabular}{cccccc} 
& 308 & 20.49 & & 15.04 & \\
& 318 & 18.46 & & 12.11 & \\
\hline 5-DAT & 328 & 14.32 & & 8.85 & \\
& 298 & 1867.3 & 98.41 & 1684.6 & 98.12 \\
& 308 & 578.4 & 96.46 & 339.2 & 95.57 \\
& 318 & 490.6 & 96.23 & 273.2 & 95.56 \\
& 328 & 233.8 & 93.87 & 124.3 & 92.86
\end{tabular}

Table 4. The results of EDX spectra for 5-DAT

\begin{tabular}{ccccc}
\cline { 3 - 5 } Blanc & Element & Weight\% & Atomic\% & Net Int. \\
\cline { 2 - 5 } & C K & 5.41 & 12.53 & 79.41 \\
& O K & 31.91 & 55.49 & 1710.73 \\
& CIK & 2.64 & 2.07 & 264.4 \\
\multirow{3}{*}{ 5-DAT } & FeK & 60.04 & 29.91 & 2159.29 \\
& C K & 3.79 & 9.26 & 73.68 \\
& O K & 30.74 & 56.3 & 2201.29 \\
& CI K & 0.30 & 0.25 & 36.01 \\
& FeK & 65.17 & 34.19 & 2857.95
\end{tabular}

\begin{tabular}{cccccccc}
\hline Schiff base & HOMO $(\mathrm{eV})$ & LUMO $(\mathrm{eV})$ & $\boldsymbol{\Delta E}(\mathrm{eV})$ & $\mathrm{X}(\mathrm{eV})$ & $\eta(\mathrm{eV})$ & $\boldsymbol{S}(\mathbf{e V})^{-1}$ & $\boldsymbol{\mu}$ \\
\hline Neutral form & -8.5398 & 3.1677 & 11.7075 & 2.6861 & 5.8538 & 0.1708 & 7.5871 \\
\hline Protonated form & -8.3193 & 1.1859 & 9.5052 & 3.5667 & 4.7526 & 0.2104 & 5.3488
\end{tabular}

Table 5. The quantum chemical parameters of 5-DAT

Table 6. Adsorption energy for studied inhibitor on Fe (110) surface obtained using the Monte Carlo simulation (all units in $\mathrm{kcal} / \mathrm{mol}$ )

\begin{tabular}{ccc}
\hline Systems & $\begin{array}{c}\text { Adsorption energy } \\
\text { Inhibitor }\end{array}$ & $\begin{array}{c}\text { Adsorption energy } \\
\text { Water }\end{array}$ \\
\hline $\mathrm{Fe}(\mathbf{1 1 0}) / 5-\mathrm{DAT} /(\mathbf{1 0 0}) \mathrm{H}_{2} \mathrm{O}$ & -2548.29 & -10.55 \\
\hline
\end{tabular}




\section{Highlights}

- 5-DAT has been prepared using 4-diethylaminobenzaldehyde and 5-amino1,3,4-thiadiazole-2-thiol.

- $\quad 3 \mathrm{mM}$ of 5-DAT molecule provided $98.9 \%$ protection against corrosion.

- $\quad$ SEM analyses used to surface characterization

- $\quad$ EIS, LSV and potentiodynamic polarization techniques were performed for electrochemical analyses

- Gaussian and Monte Carlo simulations were calculated for theoretical investigations. 


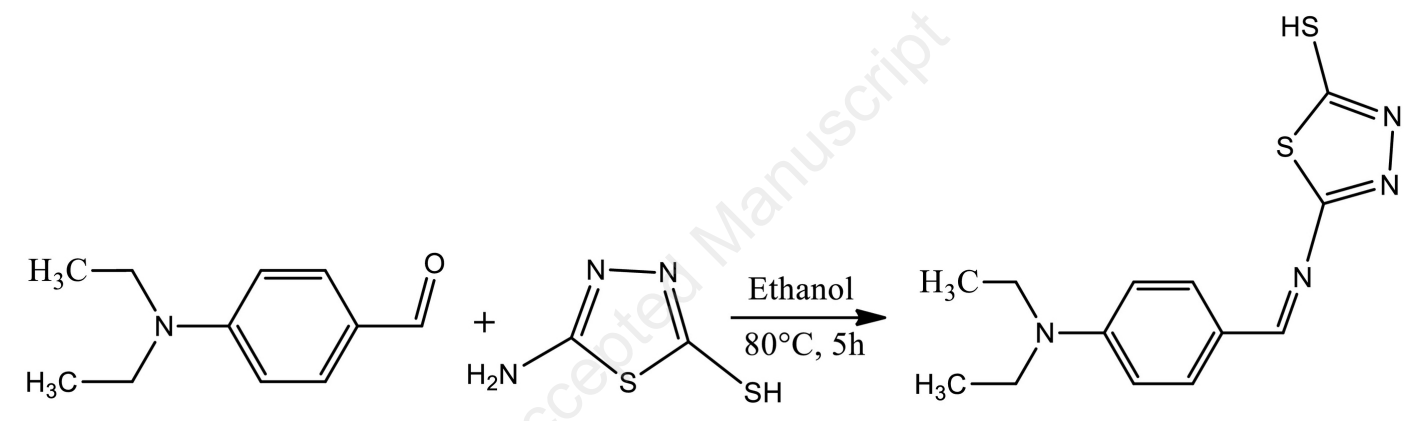

Figure 1 


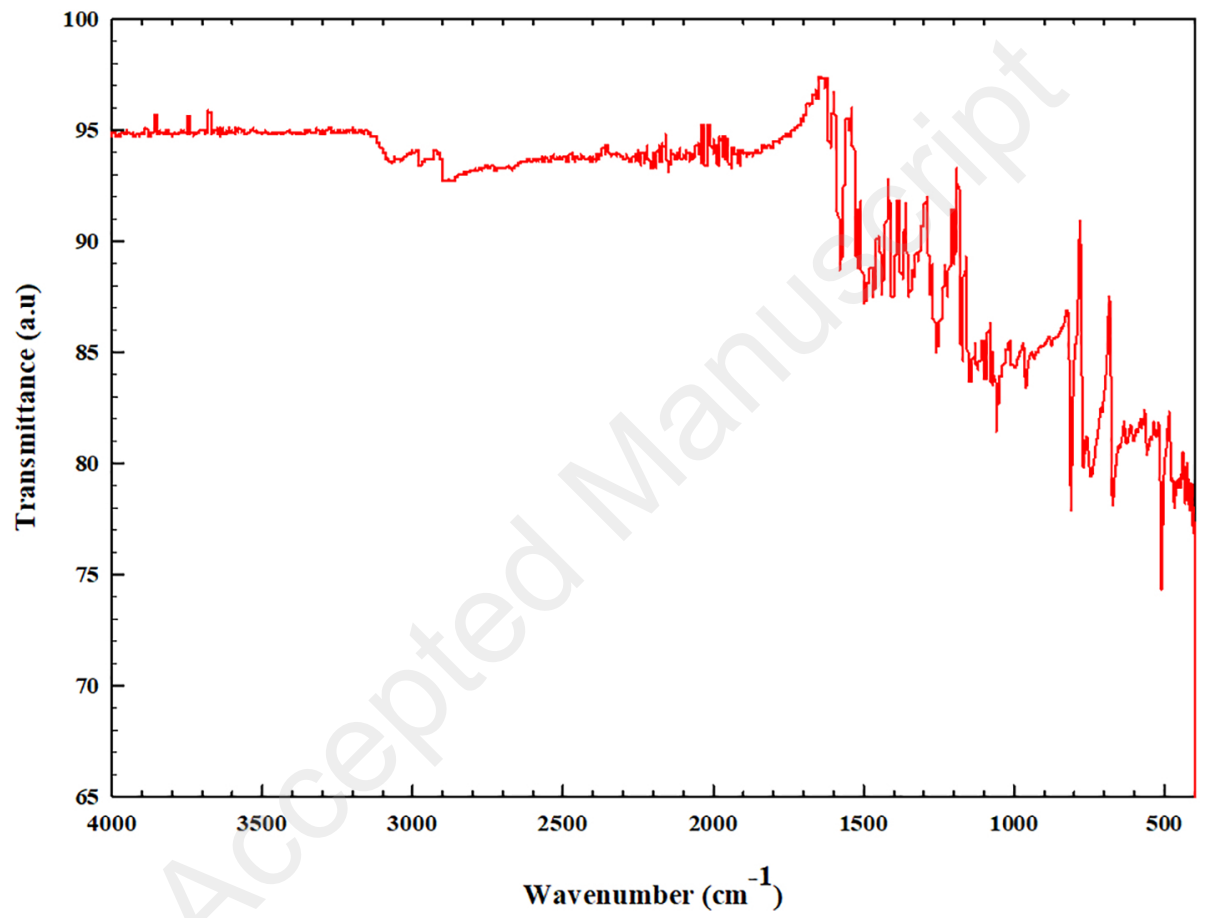

Figure 2 

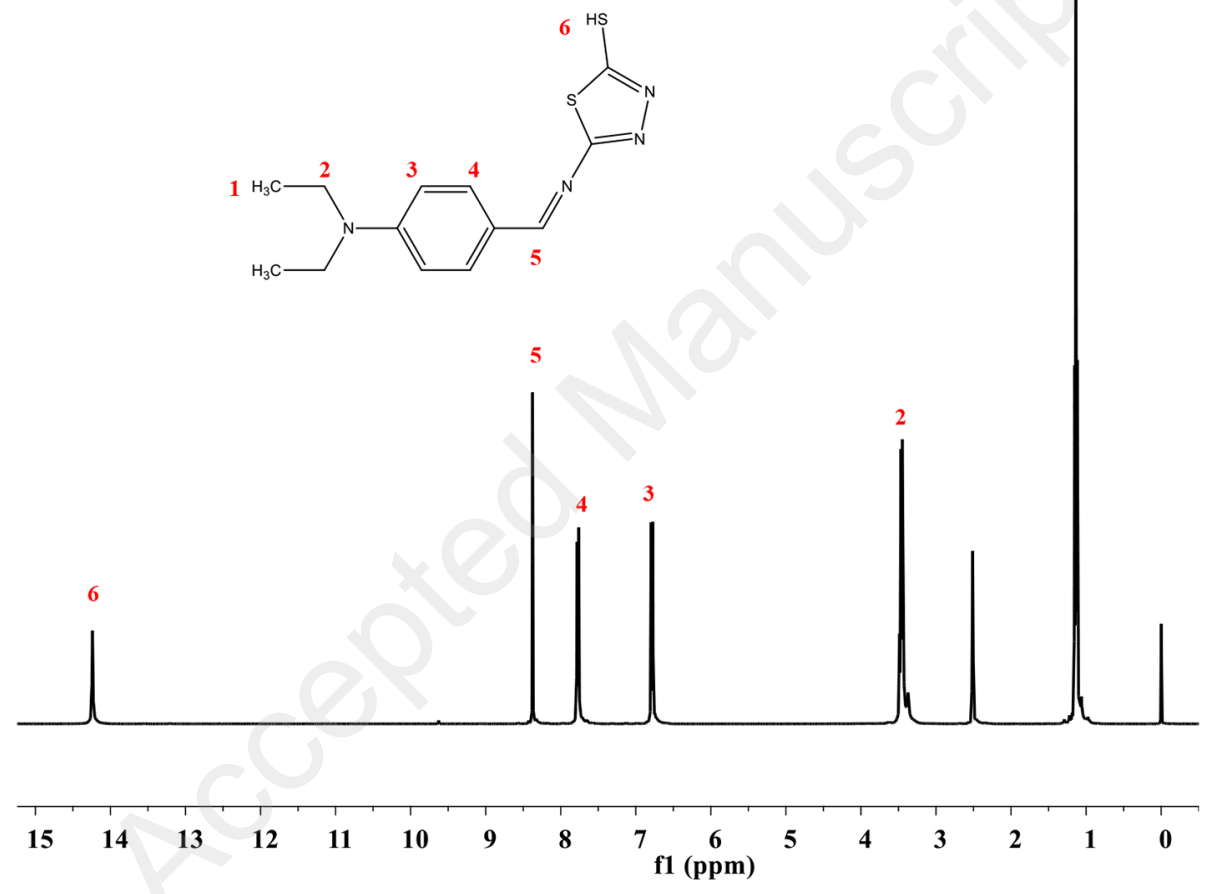

Figure 3 

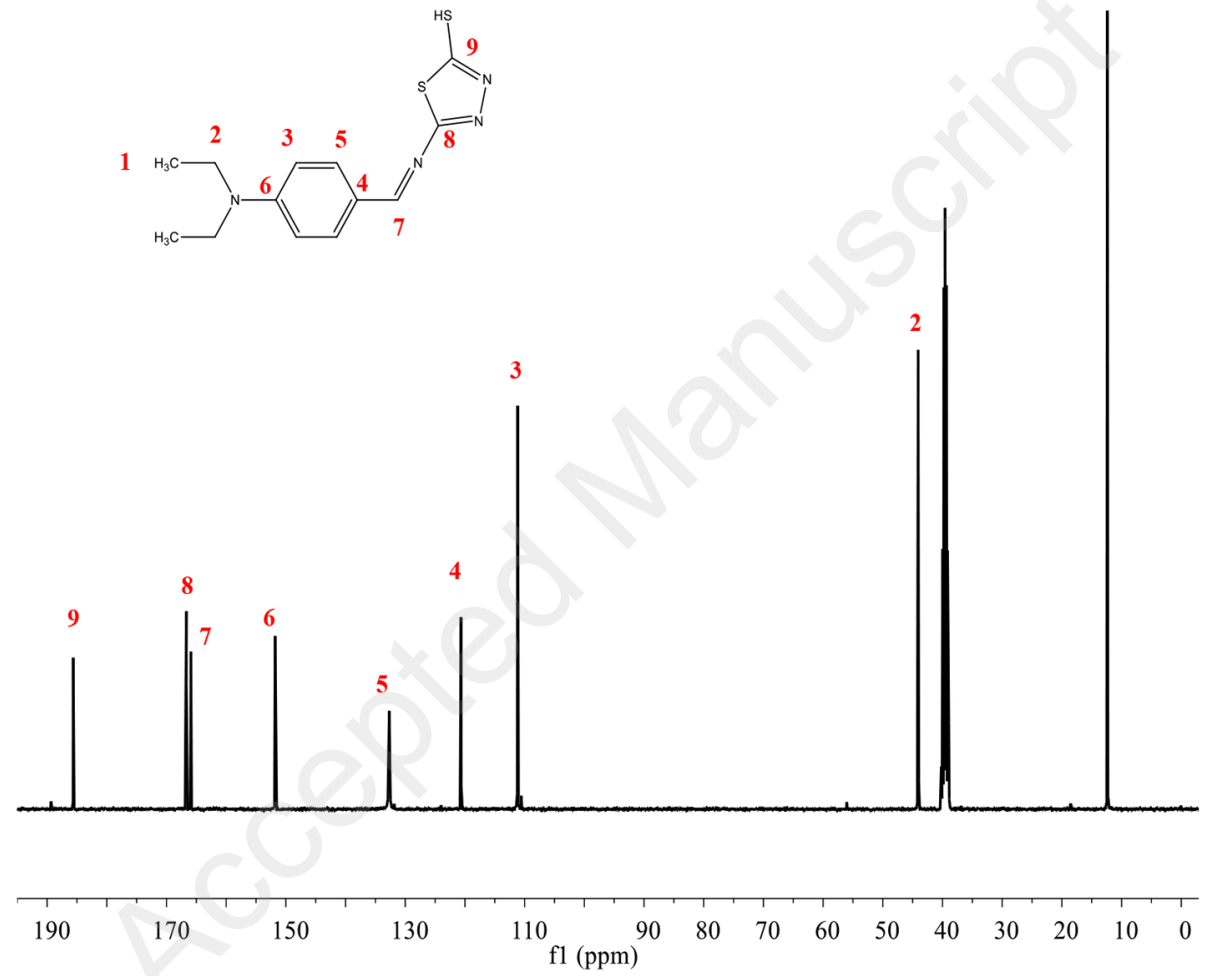

Figure 4 


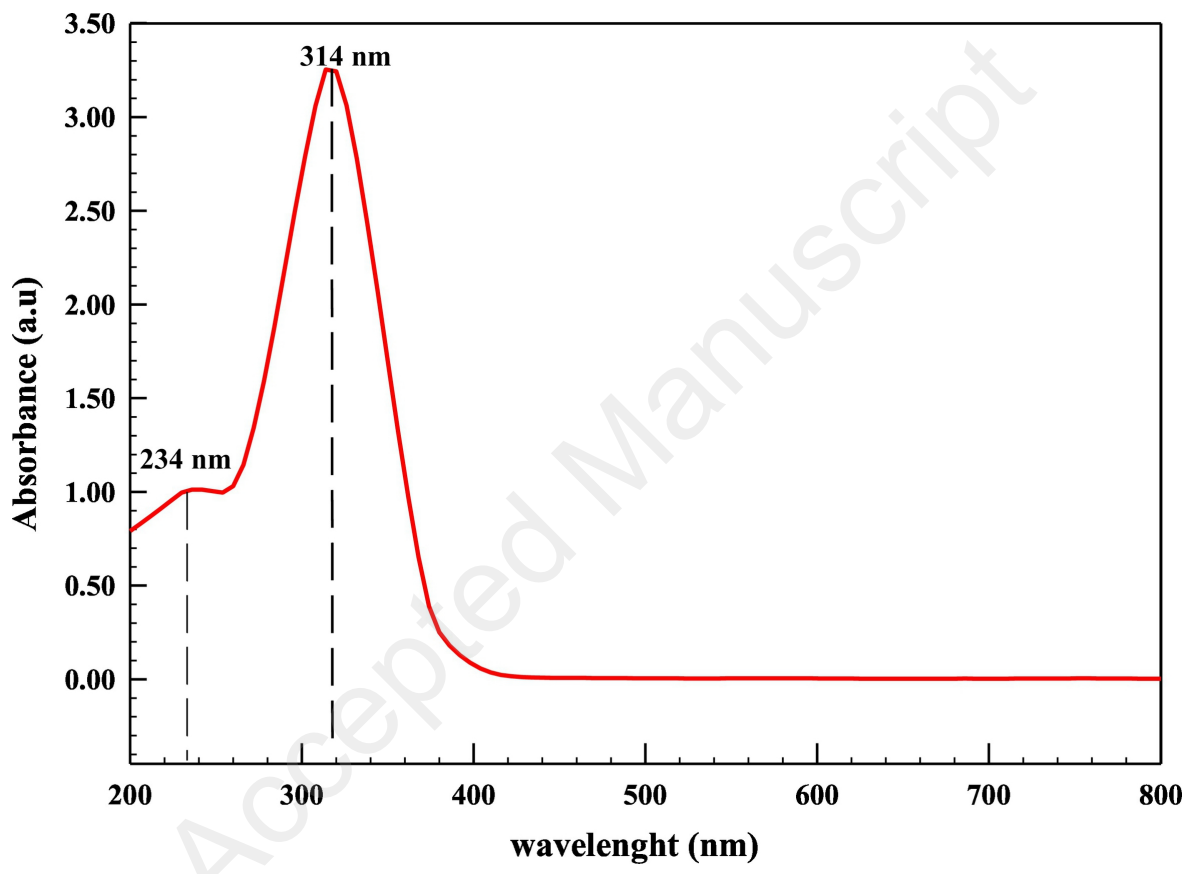

Figure 5 


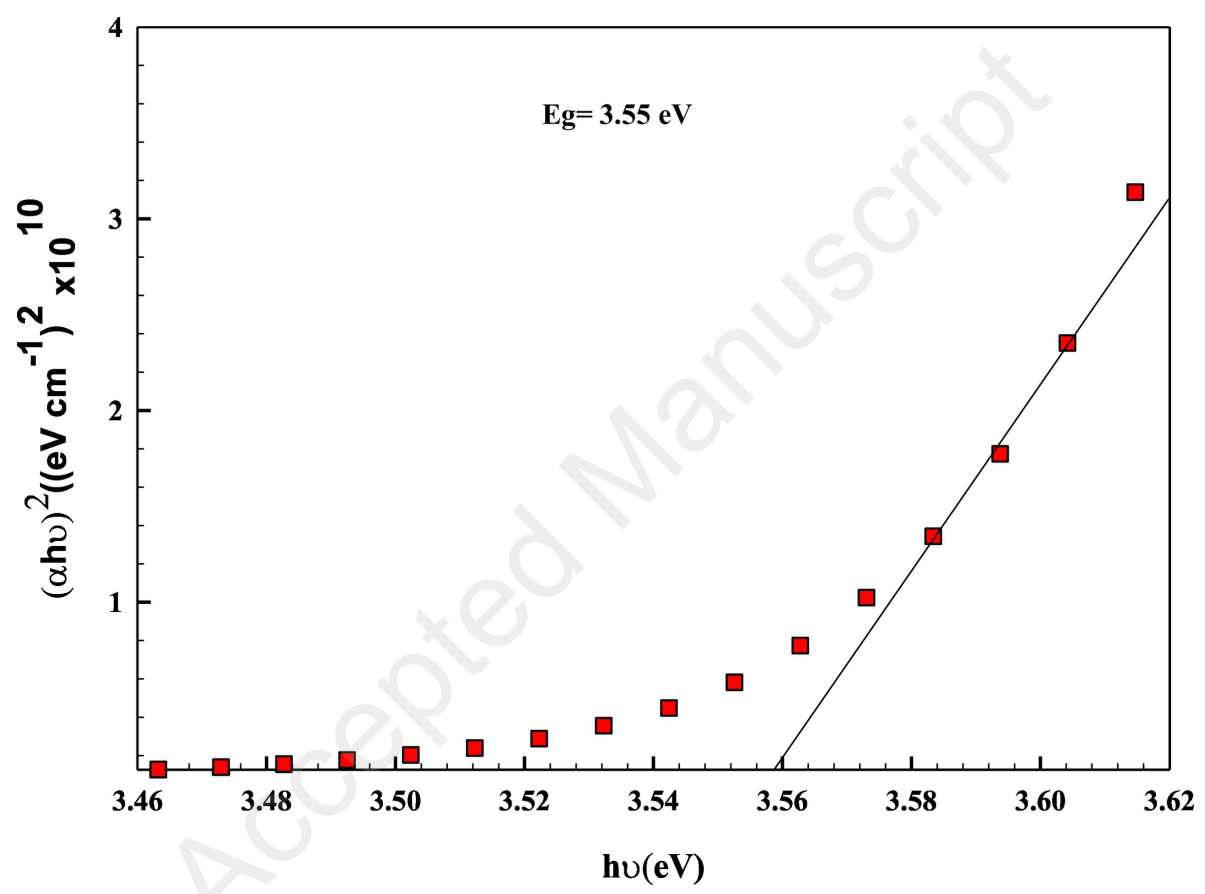

Figure 6 




Figure 7 


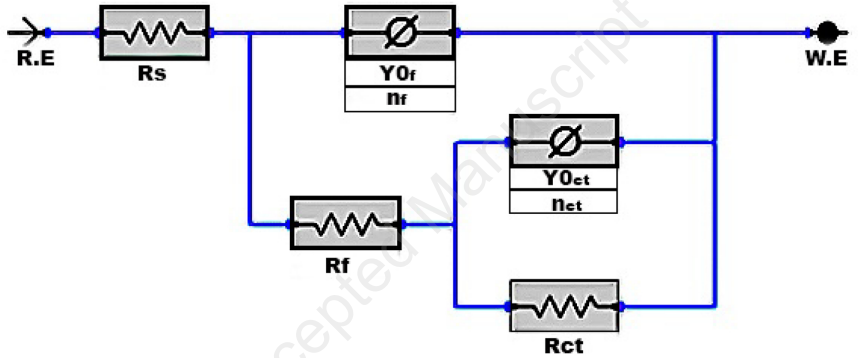

Figure 8 


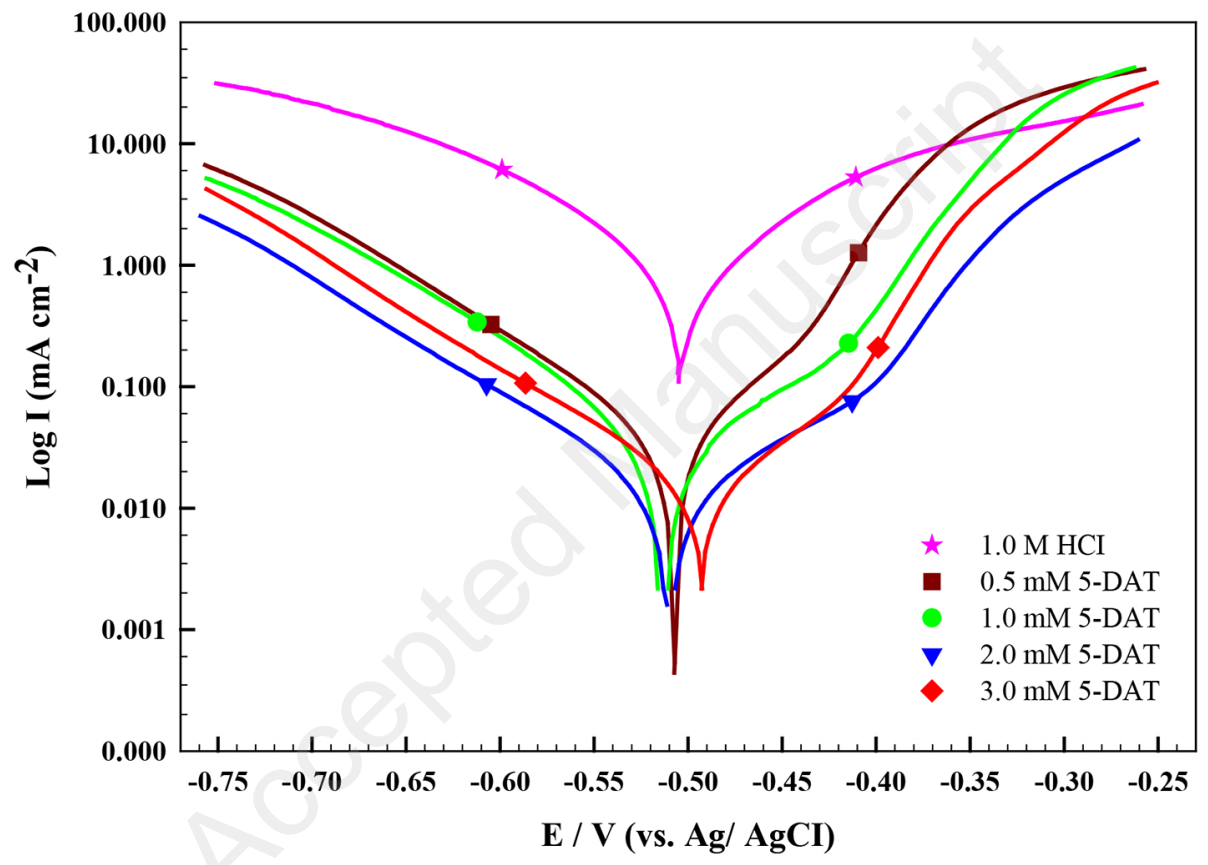

Figure 9 

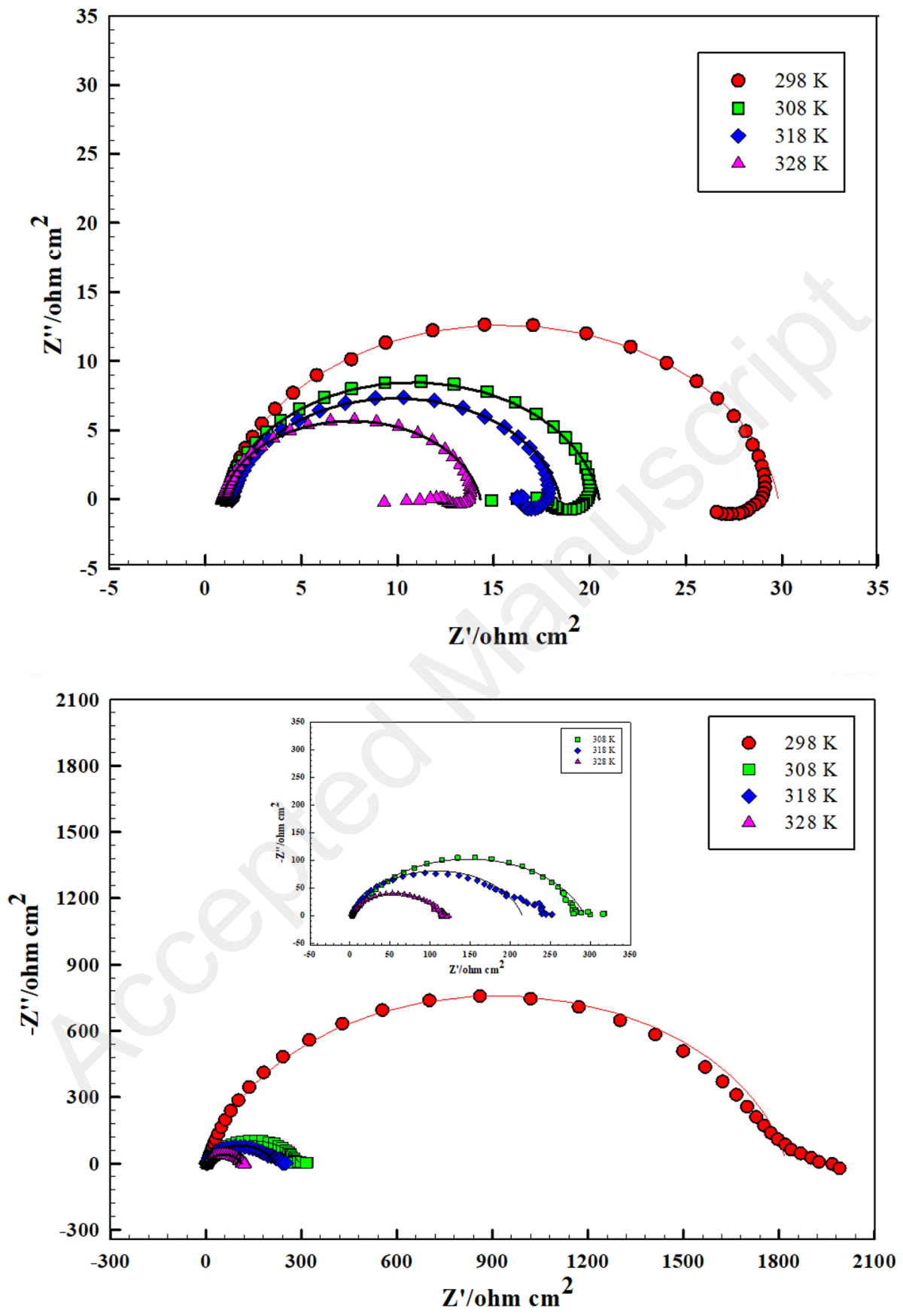

Figure 10 

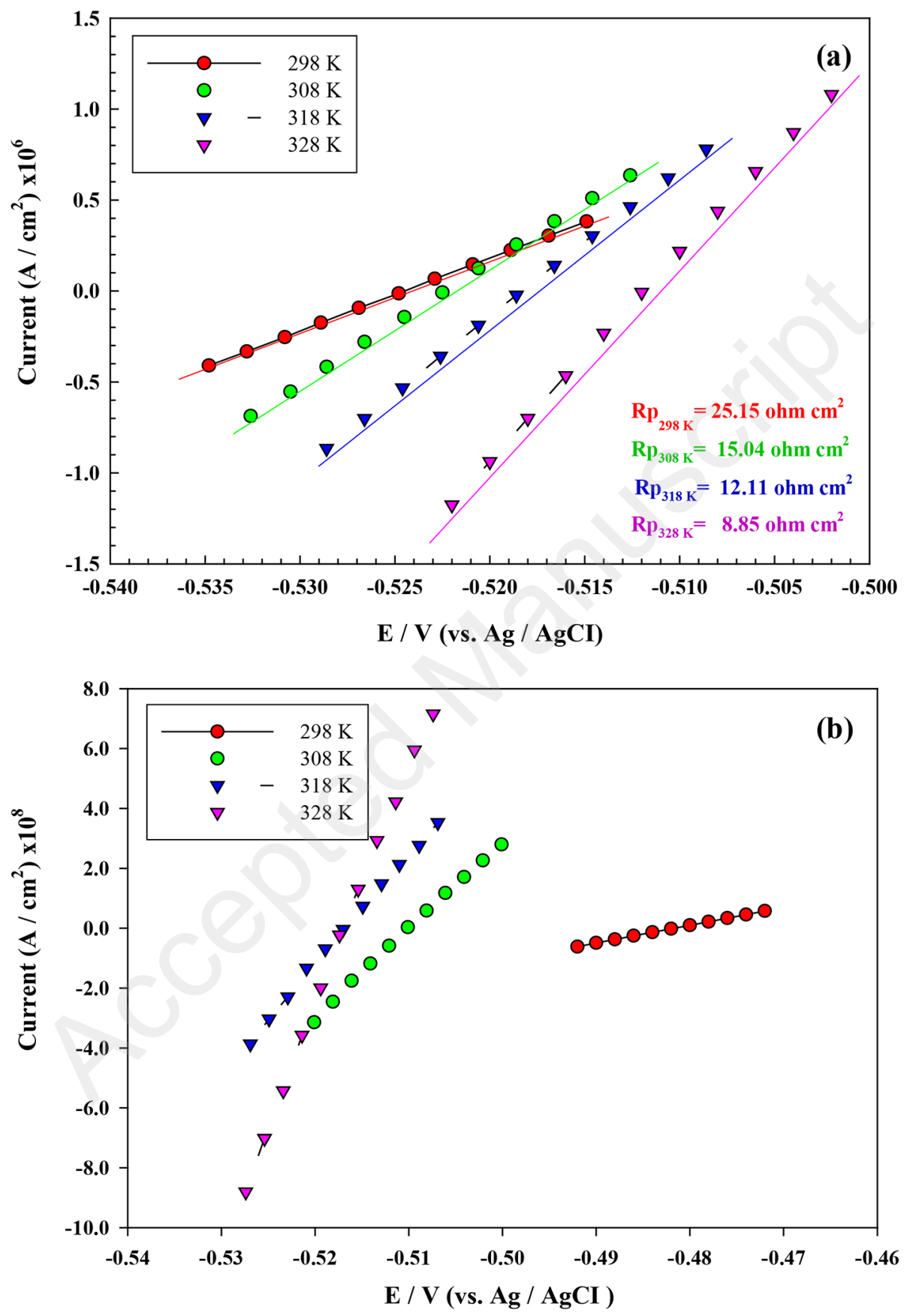


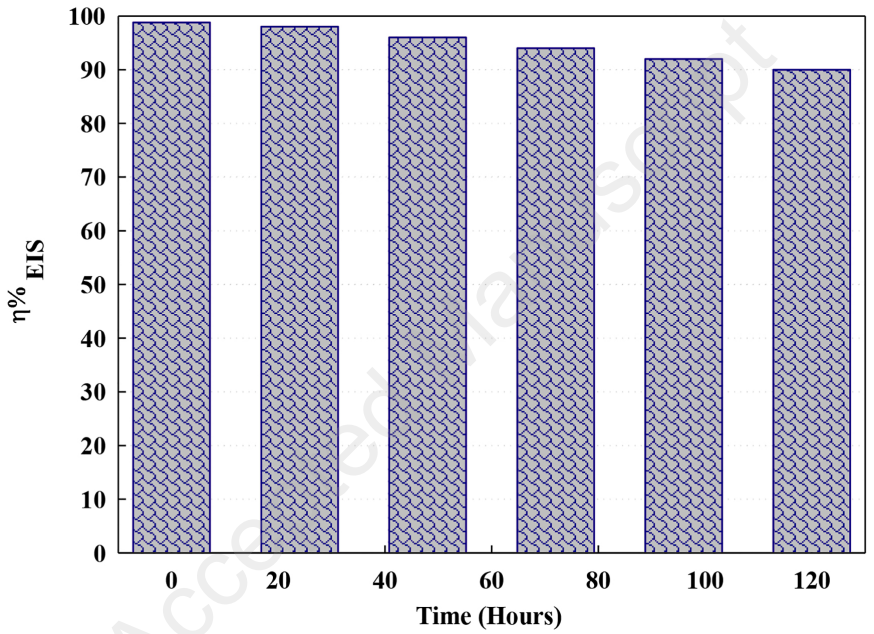

Figure 12 


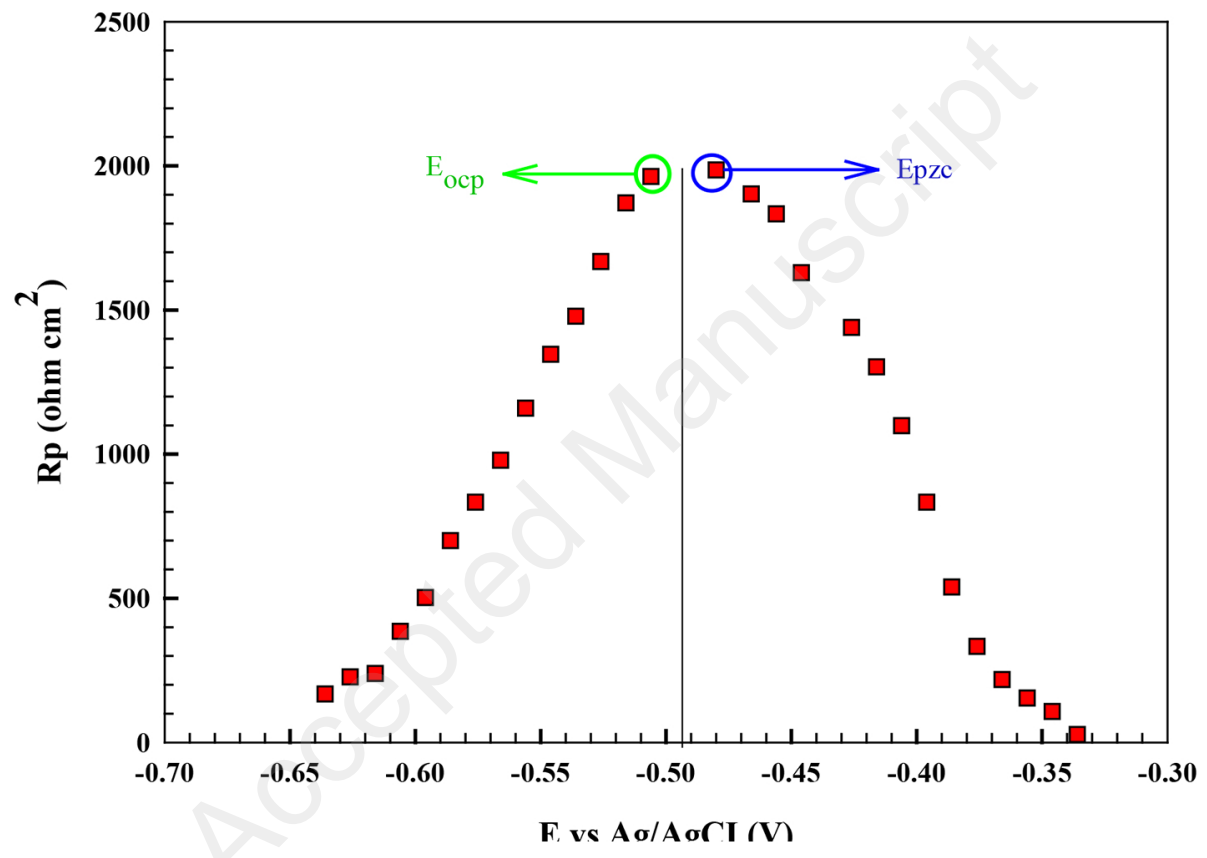

Figure 13 

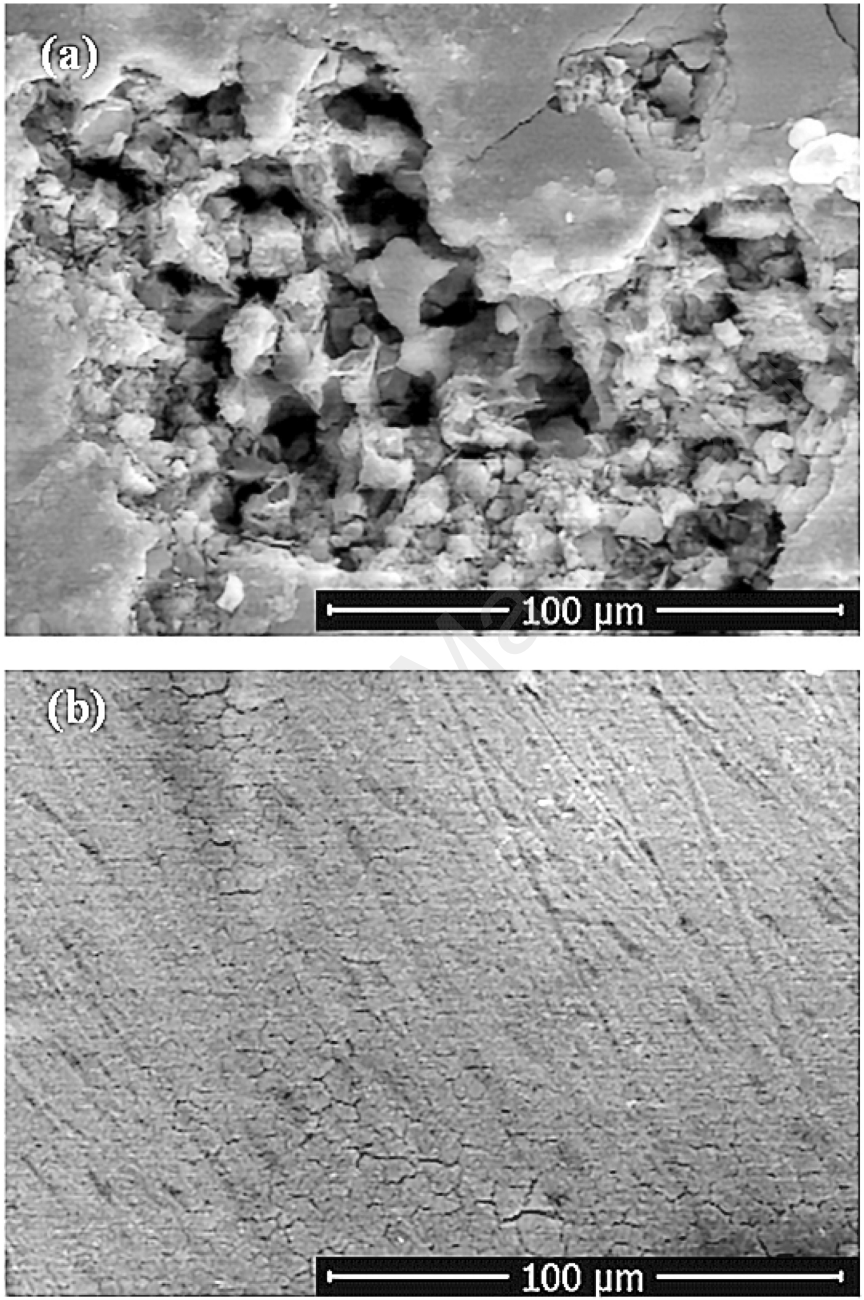


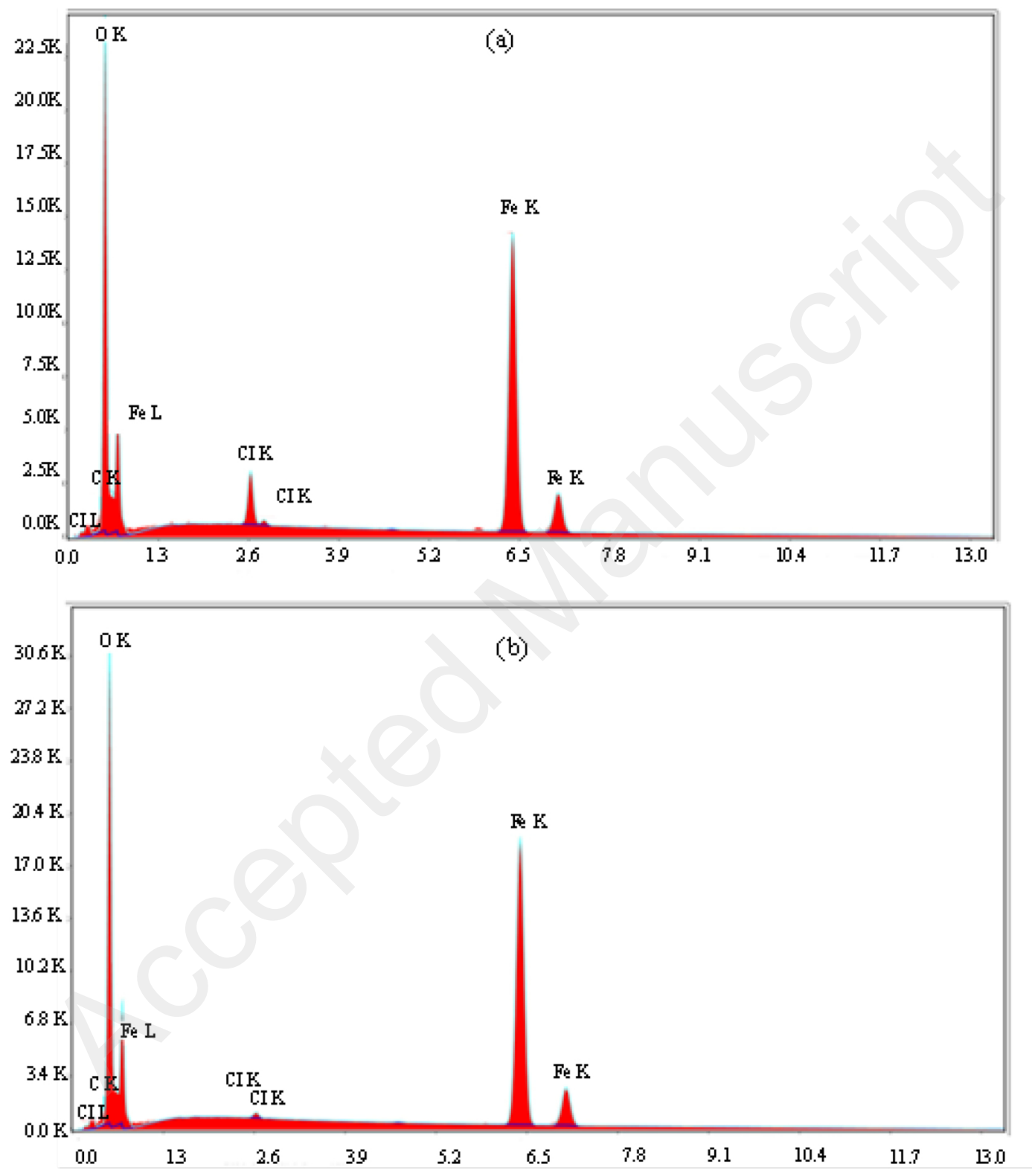

Figure 15 

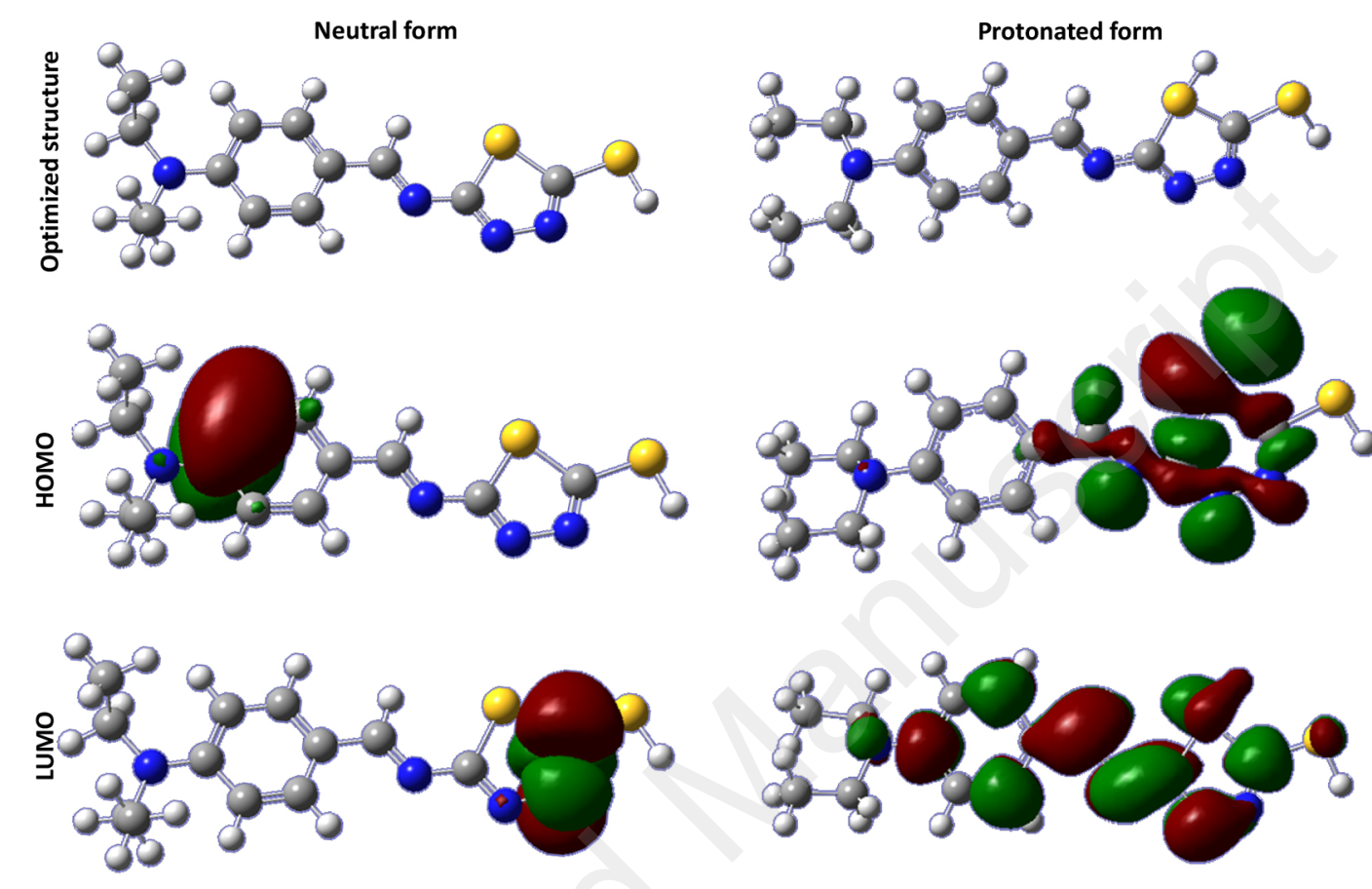

Mulliken atomic charges for neutral form

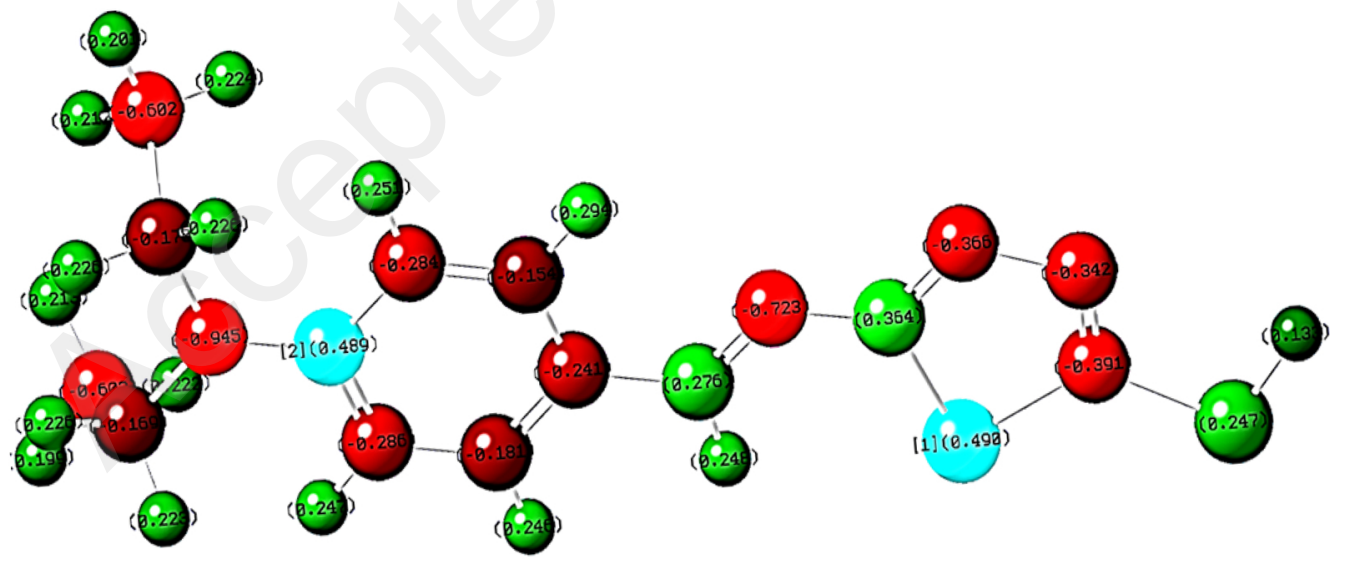

Figure 16 


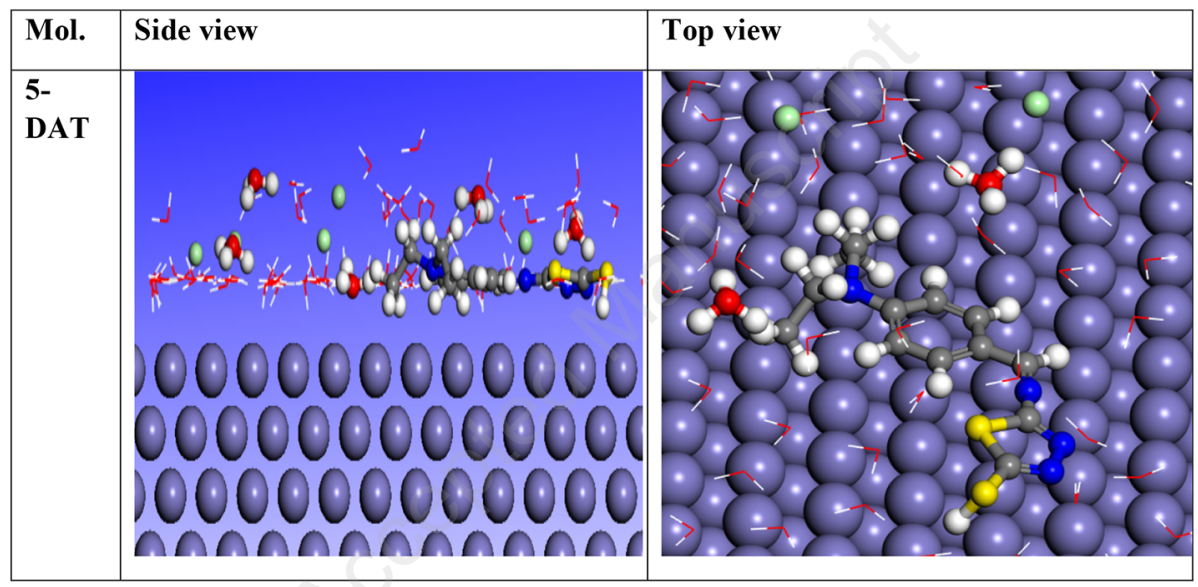

Figure 17 